\title{
The Three-Dimensional Characteristic of Fungiform Papillae and its Taste Buds in European Bison (Bison Bonasus), Cattle (Bos Taurus), and Bison Bonasus Hybrid
}

\section{Barbara Plewa}

Poznan University of Life Sciences: Uniwersytet Przyrodniczy w Poznaniu

Kinga Skieresz-Szewczyk

Poznan University of Life Sciences: Uniwersytet Przyrodniczy w Poznaniu

Hanna Jackowiak ( $\square$ hanna.jackowiak@up.poznan.pl)

Poznan University of Life Sciences https://orcid.org/0000-0001-5167-8215

\section{Research}

Keywords: fungiform papillae, taste buds, ruminants, Bison bonasus hybrid, cattle, European bison, 3Dreconstruction

Posted Date: June 2nd, 2021

DOl: https://doi.org/10.21203/rs.3.rs-528995/v1

License: (c) (1) This work is licensed under a Creative Commons Attribution 4.0 International License. Read Full License

Version of Record: A version of this preprint was published at BMC Veterinary Research on January 7th, 2022. See the published version at https://doi.org/10.1186/s12917-021-03111-5. 


\section{Abstract}

\section{Background:}

Our recent macro- and scanning electron microscopic study of tongue and lingual papillae conducted on domesticated cattle, wild living European bison, and its Bison bonasus hybrid revealed the presence of morphologic differences between parental species and the hybrid.

Analysis of gustatory papillae indicated the variable distribution of fungiform papillae (Fu) on the dorsal and ventral surface of the apex and body of the tongue to be important in taste perception during feeding and in the discussion concerning differentiated diet and living environments of studied ruminants.

To specify detailed macro-and microstructure of Fu papillae, and its connective tissue cores (CTC) and taste buds, we have chosen for the first time the three-dimensional computer-aided analysis of serial histoslides resulted in the rendering of 3D reconstructions of Fu papillae, which allowed also determine the histomorphometric characteristic of studied papillae.

\section{Results and conclusions:}

For comparative analysis of 3D models of Fu papillae and taste buds were taken from six areas of each tongue provided data about the diversity of Fu papillae in studied ruminants. The calculations of the number and density of Fu papillae of the tongues allowed us to distinguish the ventral surface of the lingual apex and posterolateral surfaces of the lingual torus as two regions important in taste perception, i.e., in the preselection of taken food and analysis of food during rumination, respectively. For the first time were indicated differences in grade of protrusion of Fu papillae over the tongue surface, the presence of three structural types of CTC, and the exact number of taste buds per papilla. The quantitative data of the number of taste buds expanded the knowledge about regional differences of the taste system. Moreover, 3D imaging resulted in the first description of variable patterns of distribution of taste buds over the surface of each Fu papillae. The comparison of obtained results determined new species-specific features in examined hybridand its similarities of some features with cattle, i.e., maternal species. The 3D reconstruction method proved to be an innovative and efficient tool in evaluating microstructures of Fu papillae, and it could be a suitable tool for further studies of gustatory papillae and taste buds in mammals.

\section{Background}

Among lingual papillae observed on mammalian tongues, fungiform papillae (Fu papillae), vallate papillae (Vp papillae), and foliate papillae (Fo papillae) belong to gustatory papillae [1]. The occurrence of each type of gustatory papillae is characteristic of taxonomic orders of mammals. Predominantly in many species of primates, carnivore, marsupials, marine mammals, suine, and rodents occur all three types of gustatory papillae $[2,3,4,5,6,7,8,9]$. However, in a while in bats, insectivores, and some carnivores (cats) or ruminants (cattle, fallow deer, Buffalo, goat, cattle-yak, yak), only Fu papillae and Vp 
papillae were observed $[10,11,12,13,14,15,16,17,18,19,20,21,22,23,24]$. An interesting exception is a hippopotamus, though it belongs to herbivores, only the presence of Fu papillae and Fo papillae were described [25].

Numerous macro- and scanning electron microscopy studies present that in mammalian species, Fu papillae are distributed only on the dorsal and ventral surface of the apex and over the body of the tongue [26]. On the dorsal surface of the apex, Fu papillae are located along lateral margins of the tongue or spread evenly among filiform papillae. The Fu papillae on the ventral surface of the tongue cover evenly lateral borders of the apex or form characteristic clusters on the anterior border of the lingual apex or the tip of the tongue $[\mathbf{8}, \mathbf{1 3}, \mathbf{2 3}, \mathbf{2 7}, \mathbf{2 8 , 2 9 ]}$. On the dorsal surface of the body of the tongue, Fu papillae are distributed regularly or only on its lateral areas. $[8, \mathbf{1 3}, \mathbf{2 7}, \mathbf{3 0}, \mathbf{3 1}]$. Fu papillae in ruminants are also observed on the dorsal and lateral surfaces of the lingual prominence $[23,31,32,33,34]$.

Previous studies on the microstructure of Fu papillae in mammals are mostly based on observations in a scanning electron microscope (SEM) and histological sections in light microscopy. In these studies, Fu papillae were described as dome-shaped structures with the convex or flat dorsal surface $[\mathbf{3}, \mathbf{8}, \mathbf{9}, \mathbf{2 7}]$, which raise above the mucosa or are deeply embedded in an interpapillary stratified squamous epithelium, so on SEM electronograms, these structures are encircled by epithelial furrow $[\mathbf{8}, \mathbf{1 2}, \mathbf{2 1}, \mathbf{2 8}$, 34]. Histologically Fu papillae are composed of connective tissue core (CTC) covered by keratinized stratified squamous epithelium containing taste buds on the dorsal surface of papilla $[26,35]$.

The main function of Fu papillae is taste perception by taste buds containing receptor cells in the cell membrane [35, 36, 37]. This function is not only connected with the choice of the best food in terms of nutrients but also with animal protection against toxins $[38,39,40]$.

So far, data about the distribution and number of taste buds on the surface of Fu papillae are insufficient. Till now, the number of taste buds was somewhat underestimated because based on the single crosssections of Fu papillae observed in light microscopy. Studies of the dorsal surface of Fu papillae in SEM showed only part of taste pores because of exfoliation of keratinized cells. However, neither of these papillae were serially cut for detailed analysis, nor the assessment of the number of taste pores on the dorsal surface of Fu papillae was reliable $[4,8,22,27,28,32,41,42]$. Thus, we decided to apply more specific and advanced method, like the three-dimensional analysis, to conducted studies.

Our previous microscopic studies of the tongue and mechanical and gustatory papillae showed the similarities and differences between closely related species of ruminants [31]. The differences in the distribution of Fu papillae in parental species, and Bison bonasus hybrid were observed on the dorsal and ventral surface of the tongue. Evenly dispersed Fu papillae on the whole dorsal surface of the apex and lingual body in Bison bonasus hybrid differ from the dense arrangement of these papillae on lateral areas of the lingual body in cattle and European bison. Significant diversities were also noticed on the ventral surface of the apex. In Bison bonasus hybrid observed V-pattern distribution of Fu papillae, whereas these papillae in cattle and European bison were arranged marginally. In turn, a similar dispersed 
arrangement of Fu papillae in all examined ruminants was observed on the dorsal surface of the medial and posterior part of lingual prominence and its lateral surfaces [31].

The aim of the present study was a detailed analysis of Fu papillae in different areas of the tongue in three species of ruminants connected with the characteristic and histomorphometric analysis of the papillae. We also want proof if three-dimensional analysis will be an efficient tool in identifying the arrangement and number of taste buds in Fu papillae and if it would be helpful in normal, pathological, or clinical assessments.

\section{Results}

\section{Microstructure of Fu papillae}

Cross-sections of Fu papillae with its 3D models from particular parts of studied ruminants tongues with its shape and structure are presented on Figures $1.1-6.3$. Figure 7 presents 3D models of three types of Fu papillae CTCs in studied ruminants. Table 1 contains the estimated number and density of Fu papillae and taste buds. The height and diameter of Fu papillae are present in Table 2. Diameters of connective tissue cores (CTCs) of Fu papillae are in Table 3. The histomorphometry of stratified squamous epithelium on Fu papillae and the height of interpapillary stratified epithelium there is in Table 4.

\section{Dorsal surface of the apex of the tongue}

In cattle, Fu papillae were spread regularly between filiform papillae on the dorsal surface of the apex. The estimated number and density of Fu papillae reached 13 and 0.5 papilla per $1 \mathrm{~cm}^{2}$, respectively (Table 1). The Fu papillae were round in outline with convex and smooth surface and $1980.7 \mu \mathrm{m}$ in height (Table 2, Fig. 1.1). In turn, the mean height of interpapillary stratified epithelium was $1567.3 \mu \mathrm{m}$, so the protrusion of Fu papillae amounted to $413.4 \mu \mathrm{m}$ (Table 4, Fig. 8A). Approximated diameter of Fu papillae was $1070.2 \mu \mathrm{m}$ (Table 2), whereas the mean diameters of CTC of these papillae reached $637.1 \mu \mathrm{m}$ in the dorsal part, $358.9 \mu \mathrm{m}$ in the medial part, and $1013.5 \mu \mathrm{m}$ in the basal part. Thus, the shape of CTC was described as balloon-like (Table 3, Figs. 1.1, 7A, 8B). The height of stratified squamous epithelium on the dorsal part of Fu papillae and its keratinized layer was $115.4 \mu \mathrm{m}$ and $17.9 \mu \mathrm{m}$, respectively (Table 4, Fig. $8 \mathrm{C})$.

In European bison, Fu papillae were also spread evenly among filiform papillae on the dorsal surface of the apex with the number of 31 and density of 0.4 papilla/ $\mathrm{cm}^{2}$ (Table 1).The Fu papillae were elliptical in outline with a convex and smooth dorsal surface (Fig. 1.2). The mean height of Fu papillae was approximately $1442.2 \mu \mathrm{m}$ (Table 2). Considering an interpapillary stratified epithelium with $1051.7 \mu \mathrm{m}$ in height, the protrusion of the papilla was $390.5 \mu \mathrm{m}$ (Table 4, Fig. 8A). The Fu papillae were $953.8 \mu \mathrm{m}$ in diameter (Table 2). Based on the diameters of its CTC in dorsal, medial, and basal part, which reached respectively $635.9 \mu \mathrm{m}, 402.4 \mu \mathrm{m}$, and $715 \mu \mathrm{m}$ balloon-like shape of CTC were distinguished (Table 3 , Figs. 1.2, 7A, 8B). An approximate height of stratified squamous epithelium and its keratinized layer on the dorsal surface of Fu papillae was $140.8 \mu \mathrm{m}$, and $20.8 \mu \mathrm{m}$, respectively (Table 4, Fig. 8C). 
The 222 evenly spread Fu papillae were observed on the dorsal surface of the Bison bonasus hybrid apex (Table 1). The approximated density of Fu papillae was nine papillae/ $\mathrm{cm}^{2}$ (Table 1). Round in outline Fu papillae characterized by flat and smooth surface (Fig. 1.3). The calculated difference between the height of Fu papillae - $1326.2 \mu \mathrm{m}$, and the height of interpapillary stratified epithelium - $1166.2 \mu \mathrm{m}$ equaled 160 $\mu \mathrm{m}$, which was the value of the papillary protrusion (Tables 2, 4, Fig. 8A). The diameter of Fu papillae ranged between $554 \mu \mathrm{m}$ and $722 \mu \mathrm{m}$, whereas the diameters of its CTC were $367.9 \mu \mathrm{m}$ in dorsal part, $334.8 \mu \mathrm{m}$ in the medial part, and $659.2 \mu \mathrm{m}$ in the basal part (Tables 2, 3). These diameters indicated the columnar-like shape of Fu papillae CTCs (Figs. 1.3, 7B, 8B). The thickness of the stratified squamous epithelium on the Fu papillae was $119.7 \mu \mathrm{m}$, whereas its keratinized layer reached $19.2 \mu \mathrm{m}$ (Table 4, Fig. $8 C)$.

\section{Ventral surface of the apex of the tongue}

In cattle, 47 Fu papillae appeared symmetrically on lateral borders of the ventral surface of the tongue, while calculated density was around 7.8 papillae/ $\mathrm{cm}^{2}$ (Table 1). Convex and smooth Fu papillae were round in outline (Fig. 2.1). The height of Fu papillae and interpapillary stratified epithelium was 1358.6 $\mu \mathrm{m}$, and $1016 \mu \mathrm{m}$, respectively (Tables 2, 4). Thus, the average protrusion was $342.2 \mu \mathrm{m}$ (Fig. 8A). The diameter of Fu papillae was $1056.2 \mu \mathrm{m}$ (Table 2). However, dimensions of CTC in its dorsal part, medial part, and basal part reached approximately $923.8 \mu \mathrm{m}, 620.1 \mu \mathrm{m}$, and $944.1 \mu \mathrm{m}$, respectively, and the balloon-like shape of CTC was described (Table 3, Figs. 2.1, 7A, 8B). The stratified squamous epithelium on the Fu papillae was $108.2 \mu \mathrm{m}$ in thickness, while its keratinized layer amounted to $11.1 \mu \mathrm{m}$ (Table 4, Fig. $8 \mathrm{C})$.

In European bison, 50 Fu papillae covered both left and right marginal areas of the ventral surface of the tongue (Table 1). Calculated density was 2.6 papillae/ $\mathrm{cm}^{2}$ (Table 1). The Fu papillae were elliptical or round in outline with a flat and smooth dorsal surface (Fig. 2.2) .Studied papillae were $1016.4 \mu \mathrm{m}$ in height, while the interpapillary stratified epithelium reached $770.8 \mu \mathrm{m}$ (Tables 2, 4). The approximate protrusion of these papillae equaled $245.6 \mu \mathrm{m}$ (Fig. 8A). The estimated diameter of Fu papillae ranged between $552 \mu \mathrm{m}$ and $1212 \mu \mathrm{m}$, whereas dimensions of CTC were $571.4 \mu \mathrm{m}$ in dorsal part, $518.3 \mu \mathrm{m}$ in medial part, and $802.5 \mu \mathrm{m}$ in basal part, thus CTC had a columnar-like shape (Tables 2, 3, Figs. 2.2, 7B, 8B). The mean thickness of the stratified squamous epithelium and its keratinized layer on the Fu papillae was $139.5 \mu \mathrm{m}$, and $14.9 \mu \mathrm{m}$, respectively (Table 4, Fig. 8C).

In the total of 220 Fu papillae were arranged in a V-letter on the ventral surface of the Bison bonasus hybrid tongue (Table 1). Additionally, two types of Fu papillae were observed. Bigger Fu papillae created a border between smooth area and areas covered by lingual papillae, while smaller Fu papillae were spread between filiform papillae. Its density reached $20 \mathrm{Fu}$ papillae/ $\mathrm{cm}^{2}$ (Table 1). Fu papillae were elliptical or round in outline, while its dorsal surface was convex and smooth (Fig. 2.3). The height of Fu papillae, interpapillary stratified epithelium, and consequently the papillary protrusion reached $1104 \mu \mathrm{m}, 930.1 \mu \mathrm{m}$, and $173.9 \mu \mathrm{m}$, respectively (Tables 2, 4, Fig. 8A). The Fu papillae diameter ranged between $490 \mu \mathrm{m}$ and $844 \mu \mathrm{m}$, while the diameters of its CTC in dorsal, medial and basal part were $481.3 \mu \mathrm{m}, 416.2$, and 682.3 
$\mu \mathrm{m}$, respectively (Tables 2, 3, Fig. 8B). Thus, the shape of CTC was columnar-like (Figs. 2.1, 7B). The thickness of the stratified squamous epithelium on the Fu papillae was $96.9 \mu \mathrm{m}$, while its keratinized layer extends between $3 \mu \mathrm{m}$ and $27 \mu \mathrm{m}$ (Table 4, Fig. 8C).

Dorsal surface of the lingual body

In cattle and European bison, Fu papillae were observed on the lateral areas of the lingual body. In contrast, in the Bison bonasus hybrid Fu papillae were distributed on the whole dorsal surface of the lingual body.

In cattle observed 35 Fu papillae with the approximated density of 0.8 papilla/ $\mathrm{cm}^{2}$ (Table 1). Round or elliptical Fu papillae in outline had convex and smooth dorsal surface (Fig. 3.1). The Fu papillae were $1343.9 \mu \mathrm{m}$ in height, while an interpapillary stratified epithelium was $1096.9 \mu \mathrm{m}$ in height, so the protrusion equaled $247 \mu \mathrm{m}$ (Tables 2, 4, Fig. 8A). The diameter of Fu papillae was $1173.1 \mu \mathrm{m}$ (Table 2). The diameters of CTC of Fu papillae were $700.4 \mu \mathrm{m}$ in dorsal part, $484.6 \mu \mathrm{m}$ in the medial part, and $1028.9 \mu \mathrm{m}$ in the basal part, which resembled balloon-like shape (Table 3, Figs. 3.1, 7A, 8B). The stratified squamous epithelium was $122.3 \mu \mathrm{m}$ in thickness, with $16.2 \mu \mathrm{m}$ of the keratinized layer. (Table 4, Fig. 8C).

In European bison, the number and density of Fu papillae were 32 and 1 papilla/cm², respectively (Table 1). The Fu papillae were round in outline with a convex and smooth dorsal surface (Fig. 3.2). The average height of these papillae and interpapillary stratified epithelium ranged between $1187 \mu \mathrm{m}-1438 \mu \mathrm{m}$, and $519 \mu \mathrm{m}-1372 \mu \mathrm{m}$, respectively (Tables 2,4 ). Thus, the approximate protrusion of Fu papillae above the epithelium was $441.1 \mu \mathrm{m}$ (Fig. 8A). The estimated diameter of Fu papillae reached $1102.5 \mu \mathrm{m}$, while CTC was columnar-like in shape with the mean dimensions - $476.5 \mu \mathrm{m}$ in dorsal part, $451.9 \mu \mathrm{m}$ in medial part, and $900.1 \mu \mathrm{m}$ in basal part (Tables 2, 3, Figs. 3.2, 7B, 8B). The thickness of stratified squamous epithelium on Fu papillae was $166.5 \mu \mathrm{m}$, while keratinized layer - $20.6 \mu \mathrm{m}$ (Table 4, Fig. 8C).

In the Bison bonasus hybrid calculated number and density of Fu papillae reached 118, and $3 \mathrm{Fu}$ papillae/ $\mathrm{cm}^{2}$, respectively (Table 1 ). Studied papillae were round in outline and had a flat and smooth dorsal surface (Fig. 3.3). Its average height ranged between $1269 \mu \mathrm{m}$ and $1380 \mu \mathrm{m}$ (Table 2). The height of the interpapillary stratified epithelium was $1221.5 \mu \mathrm{m}$. Thus the protrusion equaled $101.2 \mu \mathrm{m}$ (Table 4, Fig. 8A). The Fu papillae were $828.9 \mu \mathrm{m}$ in diameter, while the diameter of its CTC had in approximate $603.9 \mu \mathrm{m}$ in the dorsal part, $462.4 \mu \mathrm{m}$ in the medial part, and $768.5 \mu \mathrm{m}$ in the basal part (Tables 2, 3, Fig. 8B). Thus, the shape of CTC was described as balloon-like (Figs. 3.3, 7A). Obtained average values of stratified squamous epithelium and its keratinized layer thickness on Fu papillae were $118.6 \mu \mathrm{m}$ and 19 $\mu \mathrm{m}$, respectively (Table 4, Fig. 8C).

Dorsal surface of the medial part of the torus

On the torus in cattle, European bison and Bison bonasus hybrid Fu papillae were observed on the medial and posterior part of the dorsal surface and on its lateral surfaces. 
In cattle on the dorsal surface of the torus observed 15 Fu papillae, which estimated density was 0.5 papilla/ $\mathrm{cm}^{2}$ (Table 1). In outline, Fu papillae were elliptical, whereas their dorsal surface was flat and smooth (Fig. 4.1). The height of Fu papillae and interpapillary stratified epithelium reached $1319.8 \mu \mathrm{m}$, and $1006.9 \mu \mathrm{m}$, respectively (Tables 2,4 ). Furthermore, the protrusion of these papillae was $312.9 \mu \mathrm{m}$ (Fig. 8A). The diameter of Fu papillae ranged between $1361 \mu \mathrm{m}-2155 \mu \mathrm{m}$, whereas diameters of CTC in dorsal, medial, and basal part were $1404.8 \mu \mathrm{m}, 1698.1 \mu \mathrm{m}$ and $1898.5 \mu \mathrm{m}$, respectively, which gave the cone-like shape of CTC (Tables 2, 3, Figs. 4.1, 7C, 8B). The thickness of stratified squamous epithelium on the Fu papillae was $143.2 \mu \mathrm{m}$, while its keratinized layer - $29.2 \mu \mathrm{m}$ (Table 4, Fig. 8C).

In European bison, the number and density of pigmented Fu papillae were 23 and 0.8 papilla/cm², respectively (Table 1). The dorsal surface of the elliptical in outline Fu papillae was convex and irregular (Fig. 4.2). The average height of Fu papillae and interpapillary stratified epithelium with an estimated value of papillary protrusion reached $1165.8 \mu \mathrm{m}, 838.8 \mu \mathrm{m}$, and $327 \mu \mathrm{m}$, respectively (Tables 2, 4, Fig.

8A).The diameter of Fu papillae was $1628 \mu \mathrm{m}$ (Table 2). In turn, the diameter of CTC in dorsal, medial and basal part amounted to $818.1 \mu \mathrm{m}, 929.3 \mu \mathrm{m}$, and $1402.3 \mu \mathrm{m}$, respectively, which gave the cone-like shape of CTC (Table 3, Figs. 4.2, 7C, 8B). The thickness of the stratified squamous epithelium and its keratinized layer on Fu papillae was $150.6 \mu \mathrm{m}$, and $37.1 \mu \mathrm{m}$, respectively (Table 4, Fig. 8C).

The number and density of Fu papillae on the dorsal surface of the torus in the Bison bonasus hybrid reached 15 and 0.6 papilla/ $\mathrm{cm}^{2}$, respectively (Table 1 ). Fu papillae were round in outline, while its dorsal surface was flat and smooth (Fig. 4.3). The Fu papillae were $2060.1 \mu \mathrm{m}$ in height, while the height on the interpapillary stratified epithelium ranged between $1612 \mu \mathrm{m}$ and $2148 \mu \mathrm{m}$ (Tables 2, 4). Thus, the protrusion of the papillae above the epithelium equaled $162.3 \mu \mathrm{m}$ (Fig. 8A). The diameter of Fu papillae was $1357.7 \mu \mathrm{m}$, while the dorsal, medial and, a basal diameter of CTC reached $997.3 \mu \mathrm{m}, 687.6 \mu \mathrm{m}$, and $1277.9 \mu \mathrm{m}$, respectively (Tables $\mathbf{2}$, 3, Fig. 8B). Thus, the connective tissue core was balloon-like in shape (Figs. 4.3, 7A). The thickness of stratified squamous epithelium on the Fu papillae was $121.9 \mu \mathrm{m}$, while its keratinized layer reached $35.8 \mu \mathrm{m}$ (Table 4, Fig. 8C).

\section{Dorsal surface of the posterior part of the torus}

On the posterior part of cattles' torus observed 30 Fu papillae, with a density of 0.9 papillae $/ \mathrm{cm}^{2}$ (Table 1). Round in outline, Fu papillae had a convex and smooth dorsal surface (Fig. 5.1). The height of Fu papillae and interpapillary stratified epithelium was $1402.1 \mu \mathrm{m}$ and $470 \mu \mathrm{m}$, respectively (Table 2, 4). Therefore, the protrusion of these papillae equaled $932.1 \mu \mathrm{m}$ (Fig. 8A). The Fu papillae were $1095.7 \mu \mathrm{m}$ in diameter (Table 2). The approximate dimensions of CTC in dorsal, medial, and basal parts amounted to $881.9 \mu \mathrm{m}, 649.9 \mu \mathrm{m}$, and $1265.8 \mu \mathrm{m}$, which gives a balloon-like shape of CTC (Table 3, Figs. 5.1, 7A, 8B). The average thickness of the stratified squamous epithelium and its keratinized layer on the Fu papillae ranged between $47 \mu \mathrm{m}-193 \mu \mathrm{m}$ and $6 \mu \mathrm{m}-39 \mu \mathrm{m}$, respectively (Table 4, Fig. 8C).

Like cattle, the estimated density of Fu papillae in European bison was 0.9 papilla/ $\mathrm{cm}^{2}$, but the number of Fu papillae equaled 20 (Table 1). The dorsal part of rounded or elliptical in outline Fu papillae was also 
convex and smooth (Fig. 5.2). The average values of papilla height, the height of interpapillary stratified epithelium, and the protrusion of papillae above the epithelium reached $1397.4 \mu \mathrm{m}, 680.7 \mu \mathrm{m}$, and 706.7 $\mu \mathrm{m}$, respectively (Tables 2, 4, Fig. 8A). The diameter of Fu papillae ranged between $1134 \mu \mathrm{m}-1883 \mu \mathrm{m}$, while the columnar-like shape of CTC was characterized by diameters - $1439.4 \mu \mathrm{m}$ in dorsal part, 1456.2 $\mu \mathrm{m}$ in medial part, and $1769.2 \mu \mathrm{m}$ in the basal part (Tables 2, 3, Figs. 5.2, 7B, 8B). The stratified squamous epithelium was $129.5 \mu \mathrm{m}$ in height, while its keratinized layer reached $19.2 \mu \mathrm{m}$ (Table 4, Fig. $8 \mathrm{C})$.

The calculated number and density of Fu papillae in the Bison bonasus hybrid was 46 and 2.7 papillae / $\mathrm{cm}^{2}$, respectively (Table 1). The papillae were round in outline with the convex and smooth dorsal surface (Fig. 5.3). The height of studied papillae ranged between $1032 \mu \mathrm{m}-1425 \mu \mathrm{m}$, while the height of interpapillary stratified epithelium was $944.4 \mu \mathrm{m}$, so the protrusion of the papilla above the epithelium equaled $277.1 \mu \mathrm{m}$ (Tables 2, 4, Fig. 8A). The diameter of Fu papillae amounted to $895 \mu \mathrm{m}$ (Table 2). In turn, CTC had a balloon-like shape, with an approximate diameter $-662.2 \mu \mathrm{m}$ in dorsal part, $558.1 \mu \mathrm{m}$ in medial part, and $1067.4 \mu \mathrm{m}$ in the basal part (Table 3, Figs. 5.3, 7A, 8B). Furthermore, the height of stratified squamous epithelium with its keratinized layer was $113.3 \mu \mathrm{m}$, and $16.8 \mu \mathrm{m}$, respectively (Table 4, Fig. 8C).

\section{Lateral surfaces of the torus}

The 45 Fu papillae with a density of 0.9 papilla $/ \mathrm{cm}^{2}$ were regularly distributed on the lateral surfaces of cattle torus (Table 1). The Fu papillae were round in outline with a convex and smooth dorsal surface (Fig. 6.1). It reached a height of $1314 \mu \mathrm{m}$, while the height of interpapillary stratified epithelium ranged between $864 \mu \mathrm{m}-1577 \mu \mathrm{m}$ (Tables 2,4). Therefore, the papillary protrusion was $108.7 \mu \mathrm{m}$ (Fig. 8A). The Fu papillae were $1071.7 \mu \mathrm{m}$ in diameter, while the CTC was cone-like in shape, and measured $574.6 \mu \mathrm{m}$ in dorsal part, $633.2 \mu \mathrm{m}$ in medial part, and $1056.6 \mu \mathrm{m}$ in basal part (Tables 2, 3, Figs. 6.1, 7D, 8B). The thickness of stratified squamous epithelium on Fu papillae amounted to $147.1 \mu \mathrm{m}$, whereas the thickness of its keratinized layer was $31.5 \mu \mathrm{m}$ (Table 4, Fig. 8C).

In European bison approximated number of Fu papillae on the left and right surface of torus was 46, while the density reached 1.1 papilla/ $\mathrm{cm}^{2}$ (Table 1). The dorsal part of the elliptical in outline Fu papillae was convex and smooth (Fig. 6.2). The heights of Fu papillae and interpapillary stratified epithelium ranged between $1103 \mu \mathrm{m}-1717 \mu \mathrm{m}$, and $864 \mu \mathrm{m}-1423 \mu \mathrm{m}$, respectively (Tables 2, 4). Thus, the estimated protrusion of Fu papillae above the epithelium was $441.2 \mu \mathrm{m}$ (Fig. 8A). The diameter of Fu papillae reached $655.6 \mu \mathrm{m}$ (Table 2). In turn, the columnar-like shape of CTC was characterized by dimensions $-381.8 \mu \mathrm{m}$ in dorsal part, $389.8 \mu \mathrm{m}$ in medial part, and $665.9 \mu \mathrm{m}$ in basal part (Table 3, Figs. 6.2, 7B, 8B). The thickness of stratified squamous epithelium on Fu papillae with its keratinized later was $1020.9 \mu \mathrm{m}$, and $20.9 \mu \mathrm{m}$, respectively (Table 4, Fig. 8C).

The Bison bonasus hybrid total number of Fu papillae was 38, while the density reached $1.06 \mathrm{papilla} / \mathrm{cm}^{2}$ (Table 1). Round or elliptical in outline Fu papillae with flat and smooth dorsal surface were $1601.9 \mu \mathrm{m}$ in 
height (Table 2, Fig. 6.3). Furthermore, the height of the interpapillary stratified epithelium was $1408.9 \mu \mathrm{m}$, so the protrusion of the papilla was $193 \mu \mathrm{m}$ (Table 4, Fig. 8A). The Fu papillae were $964 \mu \mathrm{m}$ in medial diameter, while CTC reached $708.9 \mu \mathrm{m}$ in dorsal part, $570.6 \mu \mathrm{m}$ in medial part, and $1063.7 \mu \mathrm{m}$ in basal part, which gave the balloon-like shape of CTC (Tables 2, 3, Figs. 6.3, 7A, 8B). The thickness of the stratified squamous epithelium and its keratinized layer on Fu papillae approximate $121.2 \mu \mathrm{m}$, and 17.7 $\mu \mathrm{m}$, respectively (Table 4, Fig. $8 \mathrm{C}$ ).

\section{Taste buds}

Dorsal surface of the apex of the tongue

Three-dimensional models of Fu papillae presented variations in the arrangement of taste buds on the dorsal surface of Fu papillae in cattle, European bison, and Bison bonasus hybrid shown in Figure 1.

In cattle, three 3D models of Fu papillae showed three different patterns of distribution of taste buds. On the one hand, taste buds were arranged in the median part of the papilla in the form of strips located perpendicularly to the median line of the tongue (Fig. 1.1a). On the other hand, taste buds formed clusters centrally or on the left side of Fu papillae (Figs. 1.1b, 1.1c). The average number of taste buds was 23 (Table 1). Furthermore, the estimated density reached 20 taste buds $/ \mathrm{mm}^{2}$ (Table 1). Moreover, the average diameter of taste buds ranged between $29.9 \mu \mathrm{m}-62.9 \mu \mathrm{m}$ (Table 5).

The 3D models of Fu papillae in European bison presented 12 taste buds in average arranged in clusters on the right or left part of the papilla (Table 1, Figs. 1.2a, 1.2b). The density of taste buds on the dorsal surface of Fu papillae was 12 taste buds $/ \mathrm{mm}^{2}$ (Table 1), while the mean diameter of taste buds reached approximately $47.9 \mu \mathrm{m}$ (Table 5).

In Bison bonasus hybrid, three 3D models of Fu papillae were prepared (Figs. 1.3a, 1.3b, 1.3c). In two 3D models of these papillae, a single taste bud arranged centrally was observed (Figs. 1.3a, 1.3c). In turn, in the third one observed a lack of taste buds (Fig. 1.3b). The calculated density of taste buds in these Fu papillae was three taste buds $/ \mathrm{mm}^{2}$ (Table 1). Furthermore, the mean diameter of taste buds was $32.5 \mu \mathrm{m}$ (Table 5).

Ventral surface of the apex of the tongue

The three-dimensional reconstructions of Fu papillae on the ventral surface of the tongue in studied species of ruminants are present in Figure 2.

In cattle, the 64 taste buds, on average, were evenly arranged posteriorly or on the whole surface of the dorsal part of Fu papillae (Table 1, Figs. 2.1a, 2.1b). The density of taste buds in these papillae reached 41 taste buds $/ \mathrm{mm}^{2}$, while the diameter of taste buds was $39.5 \mu \mathrm{m}$ (Tables 1,5 ).

In European bison, taste buds were arranged anteriorly and near the right border of the dorsal surface of Fu papillae (Figs. 2.2a, 2.2b). The average number of taste buds from two 3D models was 18 taste buds, 
while their estimated density reached 20 taste buds $/ \mathrm{mm}^{2}$ (Table 1). The average diameter of taste buds was approximately $41.7 \mu \mathrm{m}$ (Table 5).

The patterns of 20 taste buds in average in Bison bonasus hybrid were arranged posteriorly in a crescent shape and on the right part of the dorsal surface of Fu papillae (Table 1, Figs. 2.3a, 2.3b). The estimated density of taste buds was 21 taste buds/ $\mathrm{mm}^{2}$ (Table 1). In turn, their mean diameter reached $42.6 \mu \mathrm{m}$ (Table 5).

Dorsal surface of the lingual body

The 3D reconstructions of Fu papillae on the lingual body with the arrangement of taste buds are in Figure 3.

The taste buds observed on 3D models of Fu papillae in cattle formed perpendicular or parallel strips concerning the median line of the tongue (Figs. 3.1a, 3.1b, 3.1c). Averaged number of taste buds was 41, while its estimated density reached 22 taste buds $/ \mathrm{mm}^{2}$ (Table 1 ). In turn, the measured diameter of taste buds ranged between $30.2 \mu \mathrm{m}-55.6 \mu \mathrm{m}$ (Table 5).

In European bison, the arrangement of taste buds on the dorsal surface of the Fu papillae was different in each of the reconstructed papillae. On the first one, taste buds were arranged posteriorly in a crescent shape (Fig. 3.2a). On the second one, taste buds formed a centrally located strip arranged perpendicularly to the median line of the tongue (Fig. 3.2b). In turn, on the third one, a group of taste buds was located on the left part of the dorsal surface of Fu papilla (Fig 3.2c). The average number of taste buds from these three models equals 10 , as same as the estimated density - 10 taste buds $/ \mathrm{mm}^{2}$ (Table 1 ). Moreover, the measured diameter of taste buds was $42.4 \mu \mathrm{m}$ (Table 5).

In the Bison bonasus hybrid, two 3D models of Fu papillae had centrally arranged taste buds (Figs. 3.3a, 3.3b). The mean number of taste buds reached 3 , while their density was five taste buds $/ \mathrm{mm}^{2}$ (Table 1). Measured and averaged diameter of taste buds approximate $45.2 \mu \mathrm{m}$ (Table 5).

Dorsal surface of the medial part of the torus

The reconstructions of Fu papillae on the dorsal surface of the torus are presented in Figure 4.

Around 13 taste buds formed clusters arranged posteriorly or centrally on the dorsal surface of Fu papillae in cattle (Figs. 4.1a, 4.1b). The density of these taste buds reached five taste buds $/ \mathrm{mm}^{2}$, while the diameter of these taste buds was $41.1 \mu \mathrm{m}$ (Tables 1, 5).

In European bison 4, taste buds were arranged on the left or central part of the dorsal surface of Fu papillae (Table 1, Figs. 4.2a, 4.2b). The estimated density of taste buds was two taste buds $/ \mathrm{mm}^{2}$, whereas its mean diameter equaled $45.1 \mu \mathrm{m}$ (Tables 1, 5). 
In Bison bonasus hybrid on two 3D models of Fu papillae, 13 taste buds arranged anteriorly were observed (Table 1, Figs. 4.3a, 4.3b, 12). The density of taste buds approximately 11 taste buds $/ \mathrm{mm}^{2}$, whereas its diameter, reached $42.2 \mu \mathrm{m}$ (Table 1, 5, Fig. 13).

Dorsal surface of the posterior part of the torus

Reconstructions of Fu papillae from the posterior surface of the torus shown in Figure 5.

The average number of 37 taste buds evenly spread on the dorsal surface of the Fu papillae in cattle present in Table 1, and Figs. 5.1a, 5.1b. Its estimated density reached 24 taste buds $/ \mathrm{mm}^{2}$, while its mean diameter ranged between $30.1 \mu \mathrm{m}-49.4 \mu \mathrm{m}$ (Tables 1, 5).

In European bison observed 14 taste buds on average were spread unevenly on the anterior, posterior, and lateral parts of the Fu papillae, creating small clusters (Table 1, Figs. 5.2a, 5.2b). The density of taste buds was four taste buds $/ \mathrm{mm}^{2}$, while its mean diameter reached $42.9 \mu \mathrm{m}$ (Tables 1, 5).

Around 13 taste buds formed vertical and circular clusters on the dorsal surface of Fu papillae in the Bison bonasus hybrid (Table 1, Figs. 5.3a, 5.3b). The estimated density of these taste buds is 11 taste buds $/ \mathrm{mm}^{2}$, whereas its diameter was $36.5 \mu \mathrm{m}$ (Tables 1, 5).

Lateral surfaces of the torus

The 3D models of Fu papillae from lateral surfaces of the torus are presented in Figure 6.

In cattle, 17 taste buds were arranged centrally and on the left side of the dorsal surface of Fu papillae (Table 1, Figs. 6.1a, 6.1b). The density of taste buds in Fu papillae reached 16 taste buds $/ \mathrm{mm}^{2}$ in average (Table 1). Furthermore, the mean diameter of taste buds amounted to $44.8 \mu \mathrm{m}$ (Tab. 5).

On two reconstructions of Fu papillae in European bison clusters of 14 in average taste buds were observed on the left side and the posterior part of Fu papilla (Table 1, Figs. 6.2a, 6.2b). The density of these taste buds equaled 18 taste buds $/ \mathrm{mm}^{2}$ (Table 1). Additionally, the measured diameter of taste buds ranged between $23.8 \mu \mathrm{m}-56.1 \mu \mathrm{m}$ (Table 5).

In the Bison bonasus hybrid, taste buds were arranged posteriorly or centrally, close to the left area of the dorsal surface of Fu papillae (Figs. 6.3a, 6.3b). Approximately 23 taste buds were observed, while its estimated density reached 19 taste buds $/ \mathrm{mm}^{2}$ (Table 1). Moreover, the mean diameter of those taste buds was $36.9 \mu \mathrm{m}$ (Table 5).

\section{Discussion}

The microstructural observations of the Fu papillae and its taste buds in cattle, European bison, and Bison bonasus hybrid revealed new detailed data, which shows further diversity of features described in our earlier morphological publication about tongues in mentioned species [31]. Based on previous data 
about different arrangements of Fu papillae between parental species and hybrid, we estimated the total number of Fu papillae and density on the whole surface of the tongue. In cattle and the European bison number of the papillae was comparable and equaled 185 and 202 papillae, respectively. In the Bison bonasus hybrid, the amount of 659 Fu papillae was 3.2 and 3.5 times higher than its parental species. Among mammals, estimation of the number of Fu papillae was conducted so far in some insectivores, rodents, carnivores, ruminants, and humans. The number of Fu papillae was 10-12 in the common shrew, 150-300 in mice, 114-221 in rat, 500 in opossum, 240-260 in cat, 250 in the dog, 424-442 in sheep, 200-250 in bovine, and around 200 in human [13, 43, 44, 45, 46, 47].

Our present analyses in parental species noted that from $51-59 \%$ of Fu papillae were situated on the anterior part of the tongue, i.e., apex and body, while in the Bison bonasus hybrid, this value goes up to $85 \%$. However, most Fu papillae of the anterior part of the tongue were on the ventral surface of the apex. We noted $72 \%$ and $38 \%$ more Fu on the ventral surface of the apex compared to dorsal in cattle, and European bison, respectively. However, the number of Fu papillae in the Bison bonasus hybrid was almost equal and reached up to 222 on the dorsal and 220 on the ventral surface of the lingual apex. It was on average six times more Fu papillae than in parental species. Moreover, the estimated density of Fu papillae on the ventral surface of the apex in Bison bonasus hybrid reached up to 50 times more concerning other parts of the tongues in studies ruminants.

It confirms earlier macroscopic and scanning electron microscopic observations on uneven distribution of Fu papillae on the lingual apex of studied ruminants and alpaca, goat, Iraqi goat, fallow deer, and Egyptian buffalo $[20,23,28,49,50]$.

According to behavioral studies on the mechanism of feeding and content of consumed food in fallow deer, it can be assumed that the ventral surface of the apex with an accumulation of Fu papillae in studied ruminants is a contacting area of food preselection before taking a bite [23, 48].

Our observations of a number of Fu papillae revealed that the second, more relevant, part of the tongue in ruminants, due to the mastication of food, is the torus of the tongue. During cyclic side-by-side jaw movements, fine particles regurgitated from rumen are again ground by the teeth and rubbed between the surface of the tongue and the palate. During this displacement of food over the surface of the torus, activation of the sensory system of Fu papillae occurs.

For the first time, our analyses characterized Fu papillae on the dorsal and lateral surfaces of the torus of the tongue. We revealed that the number and density of these papillae increase on the dorsal surface of the torus in cattle and Bison bonasus hybrid by approximately $50 \%-67 \%$ from the medial to the posterior area. In contrast, in European bison, these values in both areas were almost similar. The estimation of a number of Fu papillae in parental species showed similar values on the dorsal surface of the torus and lateral surfaces.

In parental species, data of Fu papillae dispersed on lateral surfaces of the torus of the tongue contacting with teeth during crushing of food particles showed values excessed these on the posterior part of the 
torus.

Thus, statements about the posterolateral surfaces of the lingual torus identify them as important food tasting areas during long chewing cycles because of numerous Vp papillae and numerous Fu papillae. It gives essential advice for further studies in ruminants to take samples not only from the medial surface of the torus, which is often considered as representative area but also from lateral surfaces of the torus.

The Fu papillae observed on 3D models in cattle, European bison, and Bison bonasus hybrid were predominantly round in outline with a convex or flattened dorsal surface. Generally, the Fu papillae surface was smooth except for some papillae on the medial part of the torus in European bison, where the papillae surface was irregular.

The same mushroom- or dome-shaped Fu papillae was described in mammalian species such as yak, cattle, cattle-yak, Iraqi goat, Iranian buffalo, hippopotamus, koala, arctic fox, Japanese badgers, and wild boar $[3,8,9,17,18,21,25,27,28]$.

The diameters of Fu papillae were differing over the tongue and generally ranged from $1056.2 \mu \mathrm{m}$ to $1865.6 \mu \mathrm{m}$ in cattle, $655.6 \mu \mathrm{m}$ to $1675.4 \mu \mathrm{m}$ in European bison, and $664.9 \mu \mathrm{m}$ to $1357.7 \mu \mathrm{m}$ in Bison bonasus hybrid. However, the diameters of Fu papillae in the anterior part of the tongue were lower than on torus from $18 \%$ in cattle, $23 \%$ in European bison, to even $32 \%$ in Bison bonasus hybrid.

A constant feature of all Fu papillae visible on 3D models and also in SEM was furrow encircled the upper part of papillae protruded over the surface of the interpapillary mucosal epithelium. As revealed, analysis of histological slides, the medial and basal part of each Fu papillae or rather their connective tissue cores were surrounded or even embedded in the high interpapillary multi-layered epithelium of the mucosa.

Comparing the total height of Fu papillae over the entire tongue in cattle, European bison and their hybrid showed that the average papillae height was $1453 \mu \mathrm{m}, 1353 \mu \mathrm{m}$, and $1439 \mu \mathrm{m}$, respectively. Only in cattle, the height of Fu papillae in the anterior part of the tongue was about $16 \%$ higher than on the torus. The height of Fu papillae on the torus comparing to the anterior part of the tongue was $5 \%$ higher in European bison and $23 \%$ in the hybrid.

The protrusion of the upper part of Fu papillae over the interpapillary stratified epithelium may be a good index explaining the rate of exposure of the dorsal surface of Fu papillae, containing taste buds, to taste stimuli due to food selection and/or control of swallowed food. The average protrusion in studies species was $392 \mu \mathrm{m}$ in cattle, $425 \mu \mathrm{m}$ in European bison, and only $177 \mu \mathrm{m}$ in European bison hybrid. On the anterior dorsal part of the tongue were note lower values of papillary protrusion compared to torus by approximately $46 \%$ in cattle, $20 \%$ in European bison, and $41 \%$ in Bison bonasus hybrid. Most protruded Fu papillae ranged from $706 \mu \mathrm{m}$ in European bison to $932 \mu \mathrm{m}$ in cattle on the posterior surface of the torus, which may relate to rumination processes. Furthermore, in parental species, the papillary protrusion decline between dorsal and ventral surface of the apex by $17 \%$ in cattle and $37 \%$ in European bison. Only 
on the ventral surface of the apex of the Bison bonasus hybrid, $8 \%$ higher papillary protrusion was revealed.

The correlated observations of 3D models parallel with serial 2D histoslides gave an occasion to the comparative description of two elements of Fu papillae, i.e., superficial epithelium, which contains taste buds and connective tissue cores (CTC).

The keratinized stratified squamous epithelium protects Fu papillae in ruminants against mechanical damage during chewing and rumination of food. According to our analyses, the average height of stratified squamous epithelium on Fu papillae reached $125 \mu \mathrm{m}$ in cattle, $141 \mu \mathrm{m}$ in European bison, and $115 \mu \mathrm{m}$ in the hybrid. The observations of the highest mucosal epithelium in the European bison may relate to access to structurally diverse food available in a wild environment, changing with seasons. It is opposite to livestock, which feeds on structurally similar forage. Moreover, the dorsal surface of the medial part of the torus in all studied ruminants, as mastication surface, generally had the highest ratio of the keratinized layer to total epithelium thickness. In contrast, this ratio on the ventral surface of the apex was the lowest. We also state that in cattle and Bison bonasus hybrid, these parameters were the smallest in two areas, i.e., on the ventral surface of the apex and the posterior part of the torus. The presence of only ca. 9-11 $\mu \mathrm{m}$ in height keratinized layer, especially on the ventral apex, exposing taste pores on the surface of Fu papillae during the selection of food.

The connective tissue cores (CTCs) of Fu papillae are internal skeletons for capillary networks and nerve bundles, strongly attached to mucosal epithelium. So far, the shapes of CTCs as collagenous skeleton were studied in scanning electron microscopy after $\mathrm{NaOH}$ maceration of epithelia and free cells of connective tissues in rabbit, koala, hippopotamus, goat, cattle, Reeves' muntjac deer, Japanese badgers, pig, or primates $[3,4,7,9,25,32,51]$. These results revealed different shapes of CTCs, named flower-like, balloon-like, cauliflower-like, pine-cone-like, or columnar-like $[3,4,7,9,25,32,51,52]$.

Own observations of width measurements on three levels of CTC allowed to distinguished three types of CTC of Fu papillae in the studied ruminants, i.e., balloon-like, columnar-like, and cone-like. The balloonshaped CTCs were characterized by wide base narrowing in the medial part and often expanding near or over the surface of the interpapillary epithelium. Columnar-like type of CTC was characterized by quite similar dimensions on its dorsal and medial part, but some wider on the basal part. Whereas in cone-like CTC, the width becomes smaller from base to the top.

Analyzing the types of CTCs in each studied species, we distinguished all three CTC types in European bison, balloon-like and cone-like CTCs in cattle, and columnar-like and balloon-like CTCs in Bison bonasus hybrid. The most observed type of CTC in cattle and Bison bonasus hybrid were balloon-like CTC, whereas in European bison columnar-like CTC. The Fu papillae on the dorsal and ventral surface of the lingual apex in each of examined ruminants possess balloon-like or columnar-like CTCs. On the torus of the tongue in cattle and European bison, there were the cone-like CTCs, which correspond with more minor degree of protrusion of Fu papillae over the surface of the mucosa. However, in European bison hybrid on all studied surfaces of lingual torus were only balloon-like types of CTCs. 
We observed on the surface of CTC models in all studied species, numerous elongated connective tissue processes, which get deep into the thick interpapillary epithelium. Such superficial microstructures in shape/form of vertical plices, folds, and striations providing the well attachment of the epithelia were studied previously in scanning electron microscopy $[3,4,7,9,25,32,51]$. According to Yoshimura et al. (2009) there was a primary core with numerous secondary cores in CTC of Fu papillae. Moreover, around the CTCs of Fu papillae, many papillary cores of the interpapillary epithelium were observed [25]. The observations of 3D CTCs models showed that elongated interpapillary primary cores were observed in the basal part of the balloon-like type of CTC.

In contrast, along with the cone-like type, CTCs were noticed long and numerous secondary cores, which indicated solid anchoring of Fu papillae accordingly to mechanical pressure during mastication. In the columnar-like type of CTC, the interpapillary core, as well as secondary processes, were shorter and less numerous. Additionally, the primary core of columnar-like CTCs was elongated and tightly surrounding by interpapillary epithelium. In studied ruminants, this type of CTC was observed in Fu papillae on the lingual apex, body and also on posterior and lateral surfaces of the torus. In studies of the microstructure of Fu papillae in mammalian species, determining the number and distribution of taste buds in these papillae, three methods so far were used. Primarily the analyses of taste buds were based on 2D observations of the cross-sections of Fu papillae or counting of taste pores visible on scanning electron microscopic electronograms. Such studies were conducted in Egyptian fruit bats, wild boar, pig, hippopotamus, goat, yak, wolf, and Japanese badgers $[9,15,18,25,27,29,50]$. The third method was indirect because of the $\mathrm{NaOH}$ macerated CTC of Fu papillae. The counted number of depressions in the dorsal surface of CTC were considered as places for taste buds $[3,7]$.

The results of the current study based on the three-dimensional analysis of taste buds seems to be more efficient than earlier methods used to describe the taste buds system of gustatory papillae in mammalian species. Observations of serial histoslides resulted in determining the diameter of taste buds, ranging from $33 \mu \mathrm{m}$ to $48 \mu \mathrm{m}$, which may specify the size of taste buds for ruminants independent of the thickness of the stratified squamous epithelium. Studies of 3D models of Fu papillae with marked taste buds revealed that among three examined ruminants number of taste buds differ from 1 up to 64 . In some Fu papillae in the Bison bonasus hybrid, there were no taste buds in the epithelium. The number of taste buds counted from histoslides in other mammalian species was often described as "numerous, several or few" taste buds $[4,9,18,21,28,41]$.

Estimating the number of Fu papillae and taste buds per single papilla on 3D models enabled us to calculate an approximate number of taste buds on the whole tongue. The number of Fu papillae were the highest in cattle, and in Bison bonasus hybrid and equaled 6659 and 6620, respectively, while in European bison was estimated ca. $60 \%$ fewer taste buds, i.e. 2440. Previous publication about the number of taste buds in bovine was estimated from 1580 to 1838 taste buds in Fu papillae, which seems to be underestimated compared to our results [43]. In other mammalian species, like Akkaraman sheep, described 1165-1243 taste buds, while in puppy 1444 taste buds in Fu papillae were observed [46, 53]. 
The calculated number of taste buds in the anterior part of the tongue in cattle, European bison, and its hybrid concerning taste buds on all torus surfaces was higher by $60 \%, 46 \%$, and $67 \%$, respectively. Furthermore, in all examined ruminants, the number of taste buds on the apex of the tongue similar to estimated number of Fu papillae differ between dorsal and ventral surface. The number of taste buds on the ventral apex ranged from $900-4000$ and was $60-95 \%$ higher as on the dorsal surface of the apex.

A characteristic feature observed in Fu papillae on the anterior dorsal part of the Bison bonasus hybrid tongue was a significant decrease in the number of taste buds in a single papilla. The calculation showed that in cattle and European bison, as parental species, around $94 \%$, and almost $82 \%$ more taste buds in a single papilla than in their hybrid. Moreover, Fu papillae without taste buds were revealed on the dorsal surface of the apex in the Bison bonasus hybrid.

The well-developed system of taste buds noticed in the anterior part of parental species tongues, i.e., apex and body, support data about the high number and density of Fu papillae, especially on the ventral surface of the lingual apex. It also confirms the statement that the anterior part of the tongue is an important area in the initial analysis or the process of preselection of food during food intake. On the other hand, a small number of taste buds per single papilla in the anterior dorsal surface of the examined hybrid tongue seems to be inconsistent with these assumptions. However, a large number of Fu papillae on the dorsal surface of the apex and lingual body in the Bison bonasus hybrid compensate a phenomenon of a reduced number of taste buds and in final calculations showed that the number of places of perception of taste in the hybrid may be comparable to its parental species, and precisely to cattle. Anyway, the perception of the taste of studied ruminants will be a matter for further studies on the number and types of receptors cells of taste buds.

On torus, the total number of taste buds was grown from the medial to the posterior part about 3-5 times depending on species and reached 280-1110. Moreover, in European bison and European bison hybrid, the data showed $41 \%$ and $30 \%$ higher number of taste buds on lateral surfaces than the posterior dorsal part of the torus. In mentioned species, the total number of taste buds on the whole dorsal surface of the torus is smaller than on lateral surfaces.

Functionally, the lingual torus is associated with the process of mastication of food, which was confirmed in our analysis by the smallest total number of taste buds in Fu papillae in the medial part of the torus in all studied ruminants. In some earlier studies, giant Fu papillae in the posterolateral surface of torus were observed $[25,54,55,56,57]$. Our results showed that the diameter of Fu papillae on lateral surfaces of the torus was similar or lower than on the other parts of the torus. Still, the total number of taste buds in this area was visibly higher, which indicated the importance of lateral surfaces of the torus in taste perception. These observations defined the torus as a part of the tongue significant in both mechanical and sensory functions.

The analysis of 3D models of Fu papillae allowed us to observe for the first time the exact distribution of taste buds on the dorsal surface of Fu papillae. The obtained results are exclusive because we defined the arrangement of taste buds not only as dispersed manner but often as diagonal and vertical stripes or 
clusters in various shapes. In cattle, numerous taste buds were evenly dispersed or formed clusters of taste buds in the middle part of papillae, whereas in European bison, the strips were in the middle part or on borders of Fu papillae. The sparse taste buds in European bison hybrid were positioned most often centrally. If we compare the distribution of taste buds in many parts of the tongue, one observation seems to be exceptional. The taste buds of Fu papillae on the lingual body and also on lateral surfaces of lingual torus formed strips mostly arranged perpendicularly to the direction of passage of food along with the tongue. Such tendency of grouping taste buds may allow frontal contact during transportation of food and enhance the taste perception of masticated plant food on the lingual body or during passage grinding food particles in an area between teeth and torus.

The obtained comparative data revealed some species-specific features in the Bison bonasus hybrid, which is the rare case of interspecies ruminant achieved for the first time in 1970 in Poland and still occurred in farms. The Bison bonasus hybrid called żubron was crossbred as a farm ruminant due to the desire to establish a new breed of beef cattle adapted to free breeding [58]. Considering data obtained in the Bison bonasus hybrid, quite surprising was ca. 3.5 times larger total amount of Fu papillae than in parental species, and the fact that on each part of the Bison bonasus hybrid tongue, the number and density of Fu papillae per $1 \mathrm{~cm}^{2}$ exceeded values observed in cattle and European bison. Our study showed also ca. $50 \%$ lower protrusion of Fu papillae over the mucosal epithelium on each part of the European bison hybrid tongue than in its parental species. The observations of 3D models of Fu papillae indicated a lack of taste buds in Fu papillae on the lingual apex or the presence of only balloon-like CTCs in Fu papillae on the lingual torus. These listed features may be considered as species-specific traits in Bison bonasus hybrid and with earlier described anatomical structures are new features, which arose after hybridization.

Our research has shown an interesting phenomenon of similar microstructural traits of Fu papillae between the Bison bonasus hybrid and the maternal species i.e., domesticated cattle. These common features like the number and density of Fu papillae on the torus or the thickness of the stratified squamous epithelium on Fu papillae. The final calculation of the total number of taste buds in cattle and the hybrid presented almost equal values. Such microstructural traits of Fu papillae, together with earlier observed anatomical ones for cattle and Bison bonasus hybrid, may be necessary for further discussions about possible maternal effects observed in some hybrids organism.

In conclusion, quantitative and qualitative data from microscopic observation and computer-aided analysis of 3D models of Fu papillae in three species of ruminants provided information about the diversity of the features of Fu papillae over the surface of the tongues. Two regions were special, in this respect, the ventral surface of lingual apex as well as posterolateral surfaces of the lingual torus. These regional differences obtained by calculation of Fu papillae and taste buds number connected with the analysis of the scheme of taste buds distribution may relate with feeding habits and kind of forage typical for domesticated farm species like cattle and wild living European bison. The characteristic of taste buds system in terms of number and special arrangement of taste buds indicated well developed and probably efficient system of receptions of taste in cattle and less complex system in European bison 
hybrid, which may correlate with evolutionary changes in frame of domestication. Additionally, conducted observations indicated the occurrence of differences between parental species and their hybrid, and convergence of some data in cattle and Bison bonasus hybrid might result from possible maternal influences after hybridization, which could be further structural and genetic studies.

Thanks to 3D models of Fu papillae in all studied species of ruminants, the first time described three types of CTC of Fu papillae, the number and arrangement of taste buds. It established the occurrence of taste buds in Fu papillae on the dorsal surface of the torus. Estimating the total number of taste buds on the whole tongue revealed that although European bison is a wild animal, it possesses a three times lower number of taste buds concerning cattle and Bison bonasus hybrid.

As an innovative method, the three-dimensional analysis proved to be a comprehensive tool for evaluating detailed structures of Fu papillae, i.e., the papillae outline, the shape of CTC, and distribution and number of taste buds. Based on numerous results obtained from 3D models of Fu papillae, we state that the application of this modern visualization technique is the most suitable tool to describe gustatory papillae with taste buds system in mammals.

\section{Material And Methods}

The observations and 3D models of Fu papillae were conducted on one tongue of Bison bonasus hybrid and its parental species: cattle and European bison. Each tongue was fixed in 10\% neutral formaldehyde. A total of 41 Fu papillae were dissected from the dorsal and ventral surface of the apex, body of the tongue, dorsal, posterior, and lateral surfaces of the torus for three-dimensional analysis.

Tissues dissected for histology and 3D reconstructions proceeded into paraplast. Embedded tissues were serially cut on a microtome (Leica RM 2055) into $8 \mu \mathrm{m}$ slices. All slides were dye using Masson-Goldner method and closed using synthetic resin DePex. Each slide was observed and documented using a light microscope Axioskop 2 plus (Zeiss) with digital camera Gryphax. For each section, magnification x 1.25 was used. A record of lost or unsuitable slices within serial slides was conducted. Depend on the size of Fu papilla 100-300 slices per papilla were used for reconstruction. In order to create 3D reconstructions of Fu papillae, their CTCs, and taste buds, a conversion to a single channel (green channel), an alignment, a recalculation into uniform coordinates, a segmentation, a resampling in $\mathrm{X}, \mathrm{Y}$, and $\mathrm{Z}$ direction, a surface generation and adjustments steps in professional computer software, called Amira were conducted (Thermo Fisher Scientific, ver.2020). Moreover, to better visualization of 3D models, one animation of the Fu papilla from the ventral surface of the apex in cattle also in Amira were prepared (Additional file 1)

Morphometric analysis conducted on 2 - 3 Fu papillae dissected from particular parts of examined ruminants tongues. Depended on its size, 8-10 cross-sections from the medial part of the papilla were selected. Furthermore, on each perpendicular cross-section 3-5 measurements of the height of Fu papillae and its stratified squamous epithelium, the diameter of Fu papillae, the height of interpapillary epithelium, and the diameter of taste buds were taken. These data were obtained using MultiScan computer system v.18.03 (CSS, Warsaw, Poland). Average values of obtained data with its graphical analysis were 
estimated in Microsoft Excel (2010). The number and density of Fu papillae were established from macroscopic pictures of particular parts of examined tongues, whereas the number and density of taste buds were obtained from 3D models of Fu papillae.

Anatomical nomenclature of the structures of the tongue was taken from NominaAnatomicaVeterinaria (2017) [59].

\section{Abbreviations}

CTC - connective tissue core

Fu papillae - fungiform papillae

Fo papillae - foliate papillae

LM - light microscopy

SEM - scanning electron microscopy

Vp papillae - vallate papillae

\section{Declarations}

\section{Ethics approval and consent to participate}

According to Polish law and the EU directive (no. 2010/63/EU) the experiments conducted within the study do not require approval of the Local Ethical Committee for Experiments on Animal in Poznan.

\section{Consent for publication}

Not applicable

\section{Availability of data and materials}

All data analyzed during this study are included in this published article. Any additional data are available upon request to the corresponding author.

\section{Competing interests}

The authors declare that they have no competing interests

\section{Funding}

Research conducted by the statutory funding No. 506.539.04.00 of the Faculty of Veterinary Medicine and Animal Science Poznan University of Life Sciences, Poland. 


\section{Authors' contributions}

The design and concept of the study were conceptualized by authors (BP, HJ). The collecting materials, preparation of histological slides, photographic documentation of fungiform papillae, preparation of 3D reconstructions, morphometric analysis (BP, KSS). Preparation of manuscript and corrections were provided by authors $(B P, H J)$. The authors read and approved the final manuscript.

\section{Acknowledgments}

The authors greatly appreciate Mr.Henryk Ordanik, Bison bonasus hybrid breeder, for the opportunity to get the tongues of examined hybrid used in these studies.

\section{References}

1. Kardong KV. Vertebrates. Comparative Anatomy, Function, Evolution. 6th ed. China: Mc Graw Hill; 2011.

2. Yoshimura K, Kobayashi K. A comparative morphological study on the tongue and the lingual papillae of some marine mammals - Particularly of four species of odontoceti and zalophus. Shigaku=Odontology. 1997;85:385-407

3. Kobayashi K, Kumakura M, Yoshimura K, Nonaka K, Murayama T, Henneberg M. Comparative morphological study of the lingual papillae and their connective tissue cores of the koala. Anat Embryol. 2003;206:247-254.

4. Kobayashi K, Kumakura M, Yoshimura K, Tkahashi M, Zeng JH, Kageyama I, Kobayashi K, Hama N. Comparative morphological studies on the stereo structure of the lingual papillae of selected primates using scanning electron microscopy. Ann Anat. 2004;186:525-530.

5. Kumar S, Bate LA. Scanning electron microscopy study of the tongue papillae in the pig (Sus scrofa). Microsc Res Techniq. 2004;63:253-258.

6. Jackowiak H, Godynicki S. The distribution and structure of the lingual papillae on the tongue of the bank vole Clethrionomys glareolus. Folia Morphol. 2005;64:326-333.

7. Nonaka K, Zheng JH, Kobayashi K. Comparative morphological study on the lingual papillae and their connective tissue cores in rabbits. Okijamas Folia Anat. Jpn. 2008;85:57-66.

8. Jackowiak H, Godynicki S, Skieresz-Szewczyk K, Trzcielińska-Lorych J. Scanning electron microscopic study of the lingual papillae in the Arctic Fox (Alopex lagopus L., 1758). Anat. Histol. Embryol. 2009;38:377-381.

9. Yoshimura K, Shindo J, Kageyama I. Light and scanning electron microscopic study on the tongue and lingual papillae of the Japanese badgers, Meles meles anakuma. Okijamas Folia Anat. Jpn. 2009;85:119-127.

10. Dasgupta K, Singh A, Ireland WP. Taste bud density in circumvallate and fungiform papillae of the bovine tongue. Histol Histopath. 1990;5:169-172. 
11. Pastor JF, Moro JA, Verona JAG, Gato A, Represa JJ, Barbosa E. Morphological study by scanning electron microscopy of the lingual papillae in the common European bat (Pipistrellus pipistrellus). Arch. Oral Biol. 1993;38:597-599.

12. Kurtul J, Atalgin SH. Scanning electron microscopic study on the structure of the lingual papillae of the Saanen goat. Small Rumin. Res. Elsevier. 2008;80:52-56.

13. Jackowiak H, Godynicki S, Jaroszewska M, Wilczyńska B. Scanning electron microscopy of lingual papillae in the Common shrew, Sorex araneus,L. Anat. Histol. Embryol. 2004;33:290-293.

14. Jackowiak H. Scanning electron microscopy study of the lingual papillae in the European mole (Talpa europea, L., Talpidae). Anat. Histol. Embryol. 2006;35:190-195.

15. Jackowiak H, Trzcielińska-Lorych J, Godynicki S. The microstructure of lingual papillae in the Egyptian fruit bat (Rousettus aegyptiacus) as observed by light microscopy and scanning electron microscopy. Arch Histol Cytol. 2009;72:13-21.

16. Sari EK, Harem MK, Harem IS. Characteristics of dorsal lingual papillae of Zavot cattle. J Anim Vet Adv. 2010;9:123-130.

17. Mahabady MK, Morovvati H, Khazaeil. K. A microscopic study of lingual papillae in Iranian Buffalo (Bubalus bubalus). Asian J Anim Vet Adv. 2010;5:154-161.

18. Shao B, Long R, Ding Y, Wang J, Ding L, Wang H. Morphological adaptations of yak (Bos grunniers) tongue to the foraging environment of the Qinghai-Tibetan Plateau. J. Anim. Sci. 2010;88:2594-2603.

19. Emura S, Okumura T, Chen H. Morphology of the lingual papillae in the Egyptian rousette bat (Rousettus aegyptiacus). Okijamas Folia Anat. Jpn. 2012;89:61-66.

20. Emura S, El Bakary NER. Morphology of the lingual papillae of Egyptian Buffalo (Bubalus bubalis). Okajimas Folia Anat. Jpn. 2014;91:13-17

21. Ding Y, Yu S, Shao B. Anatomical and histological characteristic of the tongue and tongue mucosa linguae in the cattle-yak (Bos taurus x Bos grunniens). Front. Biol. 2016;11:141-148.

22. El-Bakary NER, Abomandour MMA. Morphological studies of the tongue of the Egyptian Water Buffalo (Bubalus bubalis) and their lingual papillae adaptation for its feeding habits. Anat. Histol. Embryo. 2017;12:34-40.

23. Jackowiak H, Skubis J, Łakomy P, Nasiadka P, Godynicki S. Anatomy of the tongue and microstructure of the lingual papillae in the fallow deer Dama dama (Linnaeus, 1758). Mamm Biol. 2017;85:14-23.

24. Emura S. Morphology of the lingual papillae in the Asian golden cat. Okijamas Folia Anat. Jpn. 2018;95:19-22.

25. Yoshimura K, Hama N, Shindo J, Kobayashi K, Kageyama I. Light and scanning electron microscopic study on the tongue and lingual papillae of the Common hippopotamus, Hippopotamus amphibious amphibious. Anat Rec. 2009;292:921-934.

26. Samuelson DA. Textbook of Veterinary Histology. St. Louis, Missouri: Saunders Elsevier 2007. 
27. Chamorro CA, Fernandez JG, de Paz P, Pelaez B, Anel L. Scanning electron microscopy of the wild boar and pig lingual papillae. Histol Histopath. 1994;9:657-667.

28. Jabbar AJ. Macroscopical and microscopical observations of the tongue in the Iraqi Goat (Capra hircus). Int J Adv Res. 2014;2:642-648.

29. Haligur A, Ozkadif S, Alan A. Light and scanning electron microscopic study of lingual papillae in the wolf (Canis lupus). Microsc Res Tech. 2018;82:501-506.

30. Pfeiffer CJ, Levin M, Lopes MAF. Ultrastructure of the horse tongue: further observations on the lingual integumentary architecture. Atan. Histol. Embryol. 2000;29:37-43.

31. Plewa B, Jackowiak H. Macro- and microscopic study on the tongue and lingual papillae of Bison bonasus hybrid as an interspecific species (Bos Taurus x Bison bonasus). Microsc Res Tech. 2020;83:1241-1250.

32. Zheng J, Kobayashi K. Comparative morphological study on the lingual papillae and their connective tissue cores (CTC) in Reeves' muntjac deer (Muntiacus reevesi). Ann. Anat. 2006;188:555-564.

33. Harem MK, Harem IS, Sari EK, Aydin MF. Light and scanning electron microscopic study of the dorsal lingual papillae of the Goitered gazelle (Gazella subgutturosa). J Anim Vet Adv. 2011;10:1906-1913.

34. Erdogan S, Perez W. Anatomical and scanning electron microscopic studies of the tongue and lingual papillae in the chital deer (Axis axis, Erxleben 1777). Acta Zool. 2014;95:484-492.

35. Ross MH, Romrell LJ, Kaye GI. Histology. A text and atlas. 3rd ed. Baltimore, USA: Williams \& Wilkins; 1995.

36. Barlow LA. A taste for development. Neuron. 1999;22:209-212

37. Jung H, Akita K, Kim J. Spacing patterns on tongue surface - gustatory papilla. Int. J. Dev. Biol. 2004;48:157-161.

38. Rozin P. The selection of foods by rats, humans, and other animals. Advances in the Study of Behaviour. Elsevier. 1976;6:21-76.

39. Forbes JM, Kyriazakis I. Food preferences in farm animals: why don't they always choose wisely? Proceedings of the Nutrition Society. 1995;54:429-440.

40. Behrens M, Meyerhof W. Mammalian Bitter Taste Perception. In: Korsching S, Meyerhof W, editors. Chemosensory Systems in Mammals, Fishes, and Insects. Results and Problems in Cell Differentiation. Springer, Berlin, Heidelberg; 2009. p. 77-96. https://doi.org/10.1007/400_2008_5

41. Erdogan S, Perez W. Anatomical and scanning electron microscopic characteristics of the tongue in the pampas deer (Cervidae: Ozotoceros bezoarticus, Linnaeus 1758). Microsc. Res. Tech. 2013;76:1025-1034.

42. El-Sharaby AA, El-Gendy SA, Alsafy MA, Nomir AG, Wakisaka S. Morphological variations of the vallate papillae in some mammalian species. Anat. Sci. Int. 2014;89:161-170.

43. Davies RO, Kare MR, Cagan RH. Distribution of taste buds on fungiform and circumvallate papillae of bovine tongue. Anat. Rec. 1979;195:443-446. 
44. Spielman Al, Brand JG. Collection of taste tissue from mammals. In: Spielman AI, Brand JG, editors. Experimental cell biology of taste and olfaction. Current techniques and protocols. USA: CRC Press; 1995. p. 25-33. https://books.google.pl/books? id=UAoMLgi_cMgC\&printsec=frontcover\&hl=pl\#v=onepage\&q\&f=true. Accessed 22 Feb 2021.

45. Robinson PP, Winkles PA. Quantitative study of fungiform papillae and taste buds on the cat's tongue. Anat. Rec. 1990;225:108-111.

46. Unsal S, Aktumsek A, Celik I, Sur E. The number and distribution of fungiform papillae and taste buds in the tongue of young and adult Akkaraman sheep. Revue Med. Vet. 2003;154:709-714.

47. Cheng LHH, Robinson PP. The distribution of fungiform papillae and taste buds on the human tongue. Arch. Oral Biol. 1991;36:583-589. https://doi.org/10.1016/0003-9969(91)90108-7

48. Bergvall UA. Food choice in fallow deer - experimental studies of electivity. Stockholm University, Sweden. 2007. Doctoral dissertation.

49. Erdogan S, Arias SV, Perez W. Morphofunctional structure of the lingual papillae in three species of South American Camelids: Alpaca, Guanaco, and Llama. Microsc Res Tech. 2016;79:61-71

50. Mahdy MAA, Abdalla KEH, Mohamed SA. Morphological and scanning electron microscopic studies of lingual papillae of the tongue of the goat (Capra hircus). Microsc. Res. Tech. 2020;1-11. DOI: 10.1002/jemt.23649

51. Kobayashi K, Kumakura M, Yoshimura K. Stereo structural differences of lingual papillae and their connective tissue cores in three kinds of Artiodactyla. Recent Advances in Microscopy of Cells, Tissues and Organs. 1997;357-361.

52. Kobayashi K, Jackowiak H, Frackowiak H, Yoshimura K, Kumakura M, Kobayashi K. Comparative morphological study on the tongue and lingual papillae of horses (Perissodactyla) and selected ruminantia (Artiodactyla). It. J. Anat. Embryol. 2005;2:55-63.

53. Holliday JC. Total distribution of taste buds on the tongue of the Pup. Ohio Journal of Science (OJS). 1940;40:337-344.

54. Inatomi M, Kobayashi K. Comparative morphological studies on the tongue and lingual papillae of the Japanese black bear (Carnivora) and the mountain goat (Artiodactyla). Odontology. 1999;87:313328.

55. Mack A, Singh A, Gilroy C, Ireland W. Porcine lingual taste buds: a quantitative study. Anat. Rec. 1997;247:33-37.

56. Yamaguchi T, Asami T, Kobayashi K. Comparative anatomical studies on the stereo structure of the lingual papillae and their connective tissue cores in the Japanese serow and Bighorn sheep. Arch. Histol Jpn. 2002;44:127-141.

57. Yoshimura K, Kumakura M, Koizumi K, Abe T, Yamaguchi T, Kobayashi K. Comparative morphological study on the stereo-structure of the lingual papillae and their connective tissue cores of the Pronghorn. Odontology. 2000;88:47-57.

58. Krasińska M. Hybrydy żubra i bydła domowego. Wrocław: Ossolineum 1988. 
59. Nomina AnatomicaVeterinaria. $6^{\text {th }}$ Ed. Submitted by the International Committee on Gross Veterinary Anatomical Nomenclature (I.C.V.G.A.N.) to the World Association of Veterinary Anatomists. Published on the website of the W.A.V.A. 2017.

\section{Tables}

Table. 1. The number and density of fungiform papillae (Fu) and its taste buds on cattle, European bison, and Bison bonasus hybrid tongue 
Cattle

\begin{tabular}{|c|c|c|c|c|c|c|}
\hline \multirow[t]{2}{*}{$\begin{array}{l}\text { Parts of } \\
\text { tongue }\end{array}$} & $\begin{array}{l}\text { Number of } \\
\text { Fu }\end{array}$ & $\begin{array}{l}\text { Density of } \\
\text { Fu per } 1 \\
\mathrm{~cm}^{2}\end{array}$ & $\begin{array}{l}\text { Number of } \\
\text { Fu }\end{array}$ & $\begin{array}{l}\text { Density of } \\
\text { Fu per } 1 \\
\mathrm{~cm}^{2}\end{array}$ & $\begin{array}{l}\text { Number of } \\
\text { Fu }\end{array}$ & $\begin{array}{l}\text { Density of } \\
\text { Fu per } 1 \\
\mathrm{~cm}^{2}\end{array}$ \\
\hline & $\begin{array}{l}\text { Number of } \\
\text { taste buds } \\
\text { per papilla }\end{array}$ & $\begin{array}{l}\text { Density of } \\
\text { taste buds } \\
\text { per } 1 \mathrm{~mm}^{2}\end{array}$ & $\begin{array}{l}\text { Number of } \\
\text { taste buds } \\
\text { per papilla }\end{array}$ & $\begin{array}{l}\text { Density of } \\
\text { taste buds } \\
\text { per } 1 \mathrm{~mm}^{2}\end{array}$ & $\begin{array}{l}\text { Number of } \\
\text { taste buds } \\
\text { per papilla }\end{array}$ & $\begin{array}{l}\text { Density of } \\
\text { taste buds } \\
\text { per } 1 \mathrm{~mm}^{2}\end{array}$ \\
\hline $\begin{array}{l}\text { Dorsal } \\
\text { surface }\end{array}$ & 13 & 0.5 & 31 & 0.4 & 222 & 9 \\
\hline $\begin{array}{l}\text { of the } \\
\text { apex }\end{array}$ & 23 & 20 & 12 & 12 & 1 & 3 \\
\hline$x$ & $(10-31)$ & & $(7-17)$ & & $(0-1)$ & \\
\hline \multicolumn{7}{|l|}{$\begin{array}{l}\text { (Min - } \\
\text { Max) }\end{array}$} \\
\hline $\begin{array}{l}\text { Ventral } \\
\text { surface }\end{array}$ & 47 & 7.8 & 50 & 2.6 & 220 & 20 \\
\hline $\begin{array}{l}\text { of the } \\
\text { apex }\end{array}$ & 64 & 41 & 18 & 20 & 20 & 21 \\
\hline$x$ & $(47-82)$ & & $(6-30)$ & & $(10-30)$ & \\
\hline
\end{tabular}

(Min -

Max)

$\begin{array}{lllllll}\begin{array}{l}\text { Dorsal } \\ \text { surface }\end{array} & 35 & 0.8 & 32 & 1 & 118 & 3 \\ \begin{array}{l}\text { of the } \\ \text { lingual } \\ \text { body }\end{array} & 41 & 22 & 10 & 10 & 3 & 5 \\ X & (20-55) & & (5-13) & & (3-4) & \end{array}$

(Min -

Max)

$\begin{array}{lllllll}\begin{array}{l}\text { Dorsal } \\ \text { surface }\end{array} & 15 & 0.5 & 23 & 0.8 & 15 & 0.6 \\ \begin{array}{l}\text { of } \\ \text { medial } \\ \text { part of } \\ \text { torus }\end{array} & 13 & 5 & 4 & 2 & 13 & 11 \\ X & (4-22) & & (3-4) & & (5-20) & \end{array}$




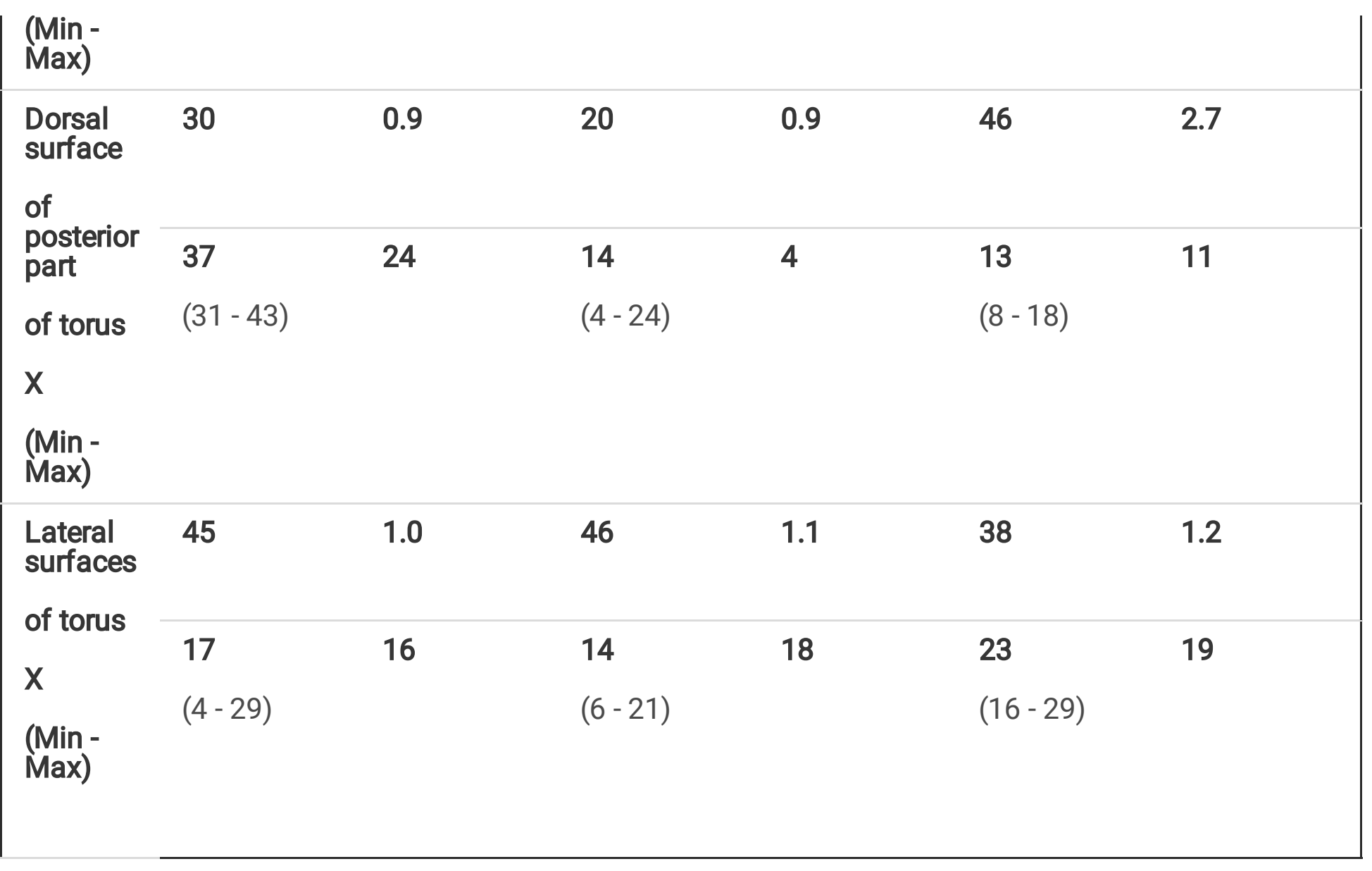

Table 2. Histomorphometry of Fu papillae on cattle, European bison, and Bison bonasus hybrid tongue 


\begin{tabular}{|c|c|c|c|c|}
\hline $\begin{array}{l}\text { Parts of } \\
\text { tongue }\end{array}$ & Fungiform papillae & Cattle & $\begin{array}{l}\text { European } \\
\text { bison }\end{array}$ & $\begin{array}{l}\text { Bison bonasus } \\
\text { hybrid }\end{array}$ \\
\hline $\begin{array}{l}\text { Dorsal } \\
\text { surface } \\
\text { of the apex }\end{array}$ & $\begin{array}{l}\text { Height of the papilla } \\
(\mu \mathrm{m})\end{array}$ & $\begin{array}{l}1980.7 \\
(1756.4- \\
2354.8)\end{array}$ & $\begin{array}{l}1442.2 \\
(1219.3- \\
1649.4)\end{array}$ & $\begin{array}{l}1326.2 \\
(1200-1406.4)\end{array}$ \\
\hline $\begin{array}{l}X \\
(\text { Min - Max) }\end{array}$ & $\begin{array}{l}\text { Diameter of the papilla } \\
(\mu \mathrm{m})\end{array}$ & $\begin{array}{l}1070.2 \\
(759.7- \\
1322.5)\end{array}$ & $\begin{array}{l}953.8 \\
(844.4- \\
1032.5)\end{array}$ & $\begin{array}{l}673.0 \\
(554.8-722.6)\end{array}$ \\
\hline $\begin{array}{l}\text { Ventral } \\
\text { surface } \\
\text { of the apex }\end{array}$ & $\begin{array}{l}\text { Height of the papilla } \\
(\mu \mathrm{m})\end{array}$ & $\begin{array}{l}1358.6 \\
(1219.3- \\
1451.6)\end{array}$ & $\begin{array}{l}1016.4 \\
(754.8- \\
1205.1)\end{array}$ & $\begin{array}{l}1104 \\
(673.1-1406.4)\end{array}$ \\
\hline $\begin{array}{l}X \\
(\text { Min - Max) }\end{array}$ & $\begin{array}{l}\text { Diameter of the papilla } \\
(\mu \mathrm{m})\end{array}$ & $\begin{array}{l}1056.2 \\
(903.2- \\
1131.7)\end{array}$ & $\begin{array}{l}990.4 \\
(522.6- \\
1212.9)\end{array}$ & $\begin{array}{l}664.9 \\
(490.3-844.1)\end{array}$ \\
\hline $\begin{array}{l}\text { Dorsal } \\
\text { surface } \\
\text { of lingual }\end{array}$ & $\begin{array}{l}\text { Height of the papilla } \\
(\mu \mathrm{m})\end{array}$ & $\begin{array}{l}1343.9 \\
(1187.1- \\
1438.7)\end{array}$ & $\begin{array}{l}1508.2 \\
(1187.0- \\
1438.7)\end{array}$ & $\begin{array}{l}1322.7 \\
(1269.2-1380.6)\end{array}$ \\
\hline (Min - Max) & $\begin{array}{l}\text { Diameter of the papilla } \\
(\mu \mathrm{m})\end{array}$ & $\begin{array}{l}1173.1 \\
(909.6- \\
1348.3)\end{array}$ & $\begin{array}{l}1102.5 \\
(909.6- \\
1348.3)\end{array}$ & $\begin{array}{l}828.9 \\
(687.9-909.6)\end{array}$ \\
\hline $\begin{array}{l}\text { Dorsal } \\
\text { surface } \\
\text { of medial part }\end{array}$ & $\begin{array}{l}\text { Height of the papilla } \\
(\mu \mathrm{m})\end{array}$ & $\begin{array}{l}1319.8 \\
(1149.3- \\
1435.0)\end{array}$ & $\begin{array}{l}1165.8 \\
(612.9- \\
1435.2)\end{array}$ & $\begin{array}{l}2060.1 \\
(1902.2-2214.9)\end{array}$ \\
\hline $\begin{array}{l}\text { torus } \\
\text { X } \\
\text { (Min - Max) }\end{array}$ & $\begin{array}{l}\text { Diameter of the papilla } \\
(\mu \mathrm{m})\end{array}$ & $\begin{array}{l}1865.6 \\
(1361.3- \\
2155.8)\end{array}$ & $\begin{array}{l}1628.0 \\
(1167.7- \\
2174.2)\end{array}$ & $\begin{array}{l}1357.7 \\
(1103.9-1593.6)\end{array}$ \\
\hline $\begin{array}{l}\text { Dorsal } \\
\text { surface } \\
\text { of posterior } \\
\text { part }\end{array}$ & $\begin{array}{l}\text { Height of the papilla } \\
(\mu \mathrm{m})\end{array}$ & $\begin{array}{l}1402.1 \\
(1013.0- \\
1629.8)\end{array}$ & $\begin{array}{l}1397.4 \\
(1032.4- \\
1717.9)\end{array}$ & $\begin{array}{l}1221.5 \\
(1032.4-1425.8)\end{array}$ \\
\hline $\begin{array}{l}\text { of torus } \\
X \\
\text { (Min - Max) }\end{array}$ & $\begin{array}{l}\text { Diameter of the papilla } \\
(\mu \mathrm{m})\end{array}$ & $\begin{array}{l}1095.7 \\
(954.2- \\
1313.7)\end{array}$ & $\begin{array}{l}1675.4 \\
(1134.6- \\
1883.1)\end{array}$ & $\begin{array}{l}895.0 \\
(792.2-1006.4)\end{array}$ \\
\hline
\end{tabular}




\begin{tabular}{lllll|}
$\begin{array}{l}\text { Lateral } \\
\text { surfaces }\end{array}$ & $\begin{array}{l}\text { Height of the papilla } \\
(\mu \mathrm{m})\end{array}$ & $\mathbf{1 3 1 4 . 0}$ & $\mathbf{1 5 8 9 . 0}$ & $\mathbf{1 6 0 1 . 9}$ \\
of torus & & $\begin{array}{l}(1078.6- \\
1649.3)\end{array}$ & $\begin{array}{l}(1103.2- \\
1717.9)\end{array}$ & $(1361.3-1771.2)$ \\
$\mathrm{X}$ & $\begin{array}{l}\text { Diameter of the papilla } \\
(\mu \mathrm{m})\end{array}$ & 1071.7 & 655.6 & 964.0 \\
$($ Min - Max $)$ & & $\begin{array}{l}(594.8- \\
1461.0)\end{array}$ & $\begin{array}{l}(564.1- \\
1461.0)\end{array}$ & $(764.7-1214.3)$ \\
\cline { 2 - 5 } & & & \\
\hline
\end{tabular}

Table 3. Diameters of CTCs in dorsal, medial and basal part of Fu papillae on cattle, European bison, and Bison bonasus hybrid tongue. 


\begin{tabular}{|c|c|c|c|c|}
\hline Parts of tongue & $\begin{array}{l}\text { Diameter of } \\
\text { CTC }\end{array}$ & Cattle & $\begin{array}{l}\text { European } \\
\text { bison }\end{array}$ & $\begin{array}{l}\text { Bison bonasus } \\
\text { hybrid }\end{array}$ \\
\hline \multirow{6}{*}{$\begin{array}{l}\text { Dorsal surface of the apex } \\
X \\
\text { (Min - Max) }\end{array}$} & \multirow[t]{2}{*}{ Dorsal part } & 637.1 & 635.9 & 367.9 \\
\hline & & $\begin{array}{l}(445.2- \\
851.6)\end{array}$ & $\begin{array}{l}(559.2- \\
743.4)\end{array}$ & $(270.9-451.6)$ \\
\hline & \multirow[t]{2}{*}{ Medial part } & 358.9 & 402.4 & 334.8 \\
\hline & & $(200-438.7)$ & $\begin{array}{l}(322,4- \\
447.4)\end{array}$ & $(232.2-458.1)$ \\
\hline & \multirow[t]{2}{*}{ Basal part } & 1013.5 & 715.0 & 659.2 \\
\hline & & $\begin{array}{l}(506.4- \\
1303.2)\end{array}$ & $\begin{array}{l}(638.7- \\
864.5)\end{array}$ & $(425.8-870.9)$ \\
\hline \multirow{6}{*}{$\begin{array}{l}\text { Ventral surface of the apex } \\
X \\
\text { (Min-Max) }\end{array}$} & \multirow[t]{2}{*}{ Dorsal part } & 923.8 & 571.4 & 481.3 \\
\hline & & $\begin{array}{l}(677.5- \\
1147.7)\end{array}$ & $\begin{array}{l}(331.2- \\
832.3)\end{array}$ & $(327.8-600.8)$ \\
\hline & \multirow[t]{2}{*}{ Medial part } & 620.1 & 518.3 & 416.2 \\
\hline & & $\begin{array}{l}(374.2- \\
862.3)\end{array}$ & $\begin{array}{l}(383.2- \\
766.2)\end{array}$ & $(339.9-483.9)$ \\
\hline & \multirow[t]{2}{*}{ Basal part } & 944.1 & 802.5 & 682.3 \\
\hline & & $\begin{array}{l}(793.5- \\
1090.3)\end{array}$ & $\begin{array}{l}(519.4- \\
935.5)\end{array}$ & $(522.6-883.1)$ \\
\hline \multirow{6}{*}{$\begin{array}{l}\text { Dorsal surface of the lingual } \\
\text { body } \\
\text { X } \\
\text { (Min - Max) }\end{array}$} & \multirow[t]{2}{*}{ Dorsal part } & 700.4 & 476.5 & 603.9 \\
\hline & & $\begin{array}{l}(599.9- \\
870.9)\end{array}$ & $\begin{array}{l}(387.1- \\
664.5)\end{array}$ & $(558.4-662.4)$ \\
\hline & \multirow[t]{2}{*}{ Medial part } & 484.6 & 451.9 & 462.4 \\
\hline & & $(400-625.8)$ & $\begin{array}{l}(290.3- \\
611.8)\end{array}$ & $(337.6-513)$ \\
\hline & \multirow[t]{2}{*}{ Basal part } & 1028.9 & 900.1 & 768.5 \\
\hline & & $\begin{array}{l}(904.4- \\
1212.9)\end{array}$ & $\begin{array}{l}(904.4 \\
-1212.9)\end{array}$ & $(643.3-870.9)$ \\
\hline \multirow{5}{*}{$\begin{array}{l}\text { Dorsal surface of medial part } \\
\text { of torus } \\
\text { X } \\
\text { (Min - Max) }\end{array}$} & \multirow[t]{2}{*}{ Dorsal part } & 1404.8 & 818.1 & 997.3 \\
\hline & & $\begin{array}{l}(1162.4- \\
1662.4)\end{array}$ & $(583.4-1329)$ & $(724.4-1188,2)$ \\
\hline & \multirow[t]{2}{*}{ Medial part } & 1698.1 & 929.3 & 687.6 \\
\hline & & $\begin{array}{l}(1305.2- \\
1909.1)\end{array}$ & $\begin{array}{l}(524.6- \\
1554.8)\end{array}$ & $(429.7-831.1)$ \\
\hline & Basal part & 1898.5 & 1402.3 & 1277.9 \\
\hline
\end{tabular}




\begin{tabular}{|c|c|c|c|c|}
\hline & & $\begin{array}{l}(1303.6- \\
2207.8)\end{array}$ & $\begin{array}{l}(1174.2- \\
2180.6)\end{array}$ & $\begin{array}{l}(1038.9- \\
1428.6)\end{array}$ \\
\hline \multirow{6}{*}{$\begin{array}{l}\text { Doral surface of posterior part } \\
\text { of torus } \\
\text { X } \\
\text { (Min - Max) }\end{array}$} & \multirow[t]{2}{*}{ Dorsal part } & 881.9 & 1439.4 & 662.2 \\
\hline & & $\begin{array}{l}(629.9- \\
1071.7)\end{array}$ & $\begin{array}{l}(910.3- \\
1764.8)\end{array}$ & $(516.5-807.9)$ \\
\hline & \multirow[t]{2}{*}{ Medial part } & 649.9 & 1456.2 & 558.1 \\
\hline & & $\begin{array}{l}(389.8- \\
831.2)\end{array}$ & $\begin{array}{l}(967.3- \\
1826.9)\end{array}$ & $(398.7-642.5)$ \\
\hline & \multirow[t]{2}{*}{ Basal part } & 1265.8 & 1769.2 & 1067.4 \\
\hline & & $\begin{array}{l}(830.9- \\
1548.9)\end{array}$ & $\begin{array}{l}(1346.1- \\
2097.4)\end{array}$ & $(883.8-1181.8)$ \\
\hline \multirow{6}{*}{$\begin{array}{l}\text { Lateral surfaces of torus } \\
X \\
\text { (Min-Max) }\end{array}$} & \multirow[t]{2}{*}{ Dorsal part } & 574.6 & 381.8 & 708.9 \\
\hline & & $\begin{array}{l}(290.4- \\
961.6)\end{array}$ & $\begin{array}{l}(294.3- \\
474.1)\end{array}$ & $(483.8-929.5)$ \\
\hline & \multirow[t]{2}{*}{ Medial part } & 633.2 & 389.8 & 570.6 \\
\hline & & $\begin{array}{l}(407.3- \\
787.1)\end{array}$ & $\begin{array}{l}(193.5- \\
551.9)\end{array}$ & $(367.8-801.3)$ \\
\hline & \multirow[t]{2}{*}{ Basal part } & 1056.6 & 665.9 & 1063.7 \\
\hline & & $\begin{array}{l}(712.4- \\
1467.5)\end{array}$ & $\begin{array}{l}(583.3- \\
1109.7)\end{array}$ & $(767.7-1400)$ \\
\hline
\end{tabular}

Table 4. The histomorphometry of interpapillary stratified epithelium and stratified squamous epithelium with keratinized layer on the dorsal surface of Fu papillae in cattle, European bison, and Bison bonasus hybrid 


\begin{tabular}{|c|c|c|c|c|}
\hline $\begin{array}{l}\text { Parts of } \\
\text { tongue }\end{array}$ & Fungiform papillae & Cattle & $\begin{array}{l}\text { European } \\
\text { bison }\end{array}$ & $\begin{array}{l}\text { Bison } \\
\text { bonasus } \\
\text { hybrid }\end{array}$ \\
\hline \multirow{2}{*}{$\begin{array}{l}\text { Dorsal surface } \\
\text { of the apex }\end{array}$} & \multirow{2}{*}{$\begin{array}{l}\text { Height of stratified squamous } \\
\text { epithelium }(\mu \mathrm{m})\end{array}$} & 115.4 & 140.8 & 119.7 \\
\hline & & $\begin{array}{l}(13.0- \\
232.6)\end{array}$ & $\begin{array}{l}(56.7- \\
286.9)\end{array}$ & $(47.6-217.3)$ \\
\hline \multirow{4}{*}{$\begin{array}{l}X \\
\text { (Min - Max) }\end{array}$} & \multirow{2}{*}{$\begin{array}{l}\text { Height of the keratinized layer of } \\
\text { the epithelium }[\mu \mathrm{m}]\end{array}$} & 17.9 & 20.8 & 19.2 \\
\hline & & $\begin{array}{l}(10.8- \\
32.1)\end{array}$ & $\begin{array}{l}(11.5- \\
63.5)\end{array}$ & $(5.8-40.3)$ \\
\hline & \multirow{2}{*}{$\begin{array}{l}\text { Height of interpapillary epithelium } \\
(\mu \mathrm{m})\end{array}$} & 1567.3 & 1051.7 & 1166.2 \\
\hline & & $\begin{array}{l}(1506.4- \\
2341.9)\end{array}$ & $\begin{array}{l}(741.9- \\
1253.9)\end{array}$ & $\begin{array}{l}(987.1- \\
1316.1)\end{array}$ \\
\hline \multirow{2}{*}{$\begin{array}{l}\text { Ventral } \\
\text { surface } \\
\text { of the apex }\end{array}$} & \multirow{2}{*}{$\begin{array}{l}\text { Height of stratified squamous } \\
\text { epithelium }(\mu \mathrm{m})\end{array}$} & 108.2 & 139.5 & 96.9 \\
\hline & & $\begin{array}{l}(48.4- \\
214.5)\end{array}$ & $\begin{array}{l}(65.3- \\
264.9)\end{array}$ & $(31.6-265.5)$ \\
\hline \multirow{4}{*}{$\begin{array}{l}X \\
\text { (Min - Max) }\end{array}$} & \multirow{2}{*}{$\begin{array}{l}\text { Height of keratinized layer of } \\
\text { epithelium }(\mu \mathrm{m})\end{array}$} & 11.1 & 14.9 & 9.2 \\
\hline & & $(4.8-22.4)$ & $\begin{array}{l}(5.1- \\
33.9)\end{array}$ & $(3.6-27.6)$ \\
\hline & \multirow{2}{*}{$\begin{array}{l}\text { Height of interpapillary epithelium } \\
(\mu \mathrm{m})\end{array}$} & 1016.4 & 770.8 & 930.1 \\
\hline & & $\begin{array}{l}(726.5- \\
1378.0)\end{array}$ & $\begin{array}{l}(309.6- \\
1149.3)\end{array}$ & $\begin{array}{l}(593.5- \\
1167.7)\end{array}$ \\
\hline \multirow{2}{*}{$\begin{array}{l}\text { Dorsal surface } \\
\text { of lingual } \\
\text { body }\end{array}$} & \multirow{2}{*}{$\begin{array}{l}\text { Height of stratified squamous } \\
\text { epithelium }(\mu \mathrm{m})\end{array}$} & 122.3 & 166.5 & 118.6 \\
\hline & & $\begin{array}{l}(40.4- \\
304.3)\end{array}$ & $\begin{array}{l}(67.7- \\
276.9)\end{array}$ & $(41.3-188.4)$ \\
\hline \multirow{4}{*}{$\begin{array}{l}X \\
\text { (Min - Max) }\end{array}$} & \multirow{2}{*}{$\begin{array}{l}\text { Height of keratinized layer of } \\
\text { epithelium }(\mu \mathrm{m})\end{array}$} & 16.2 & 20.6 & 19.0 \\
\hline & & $(6.6-30.4)$ & $\begin{array}{l}(9.6- \\
32.6)\end{array}$ & $(8.2-42.2)$ \\
\hline & \multirow{2}{*}{$\begin{array}{l}\text { Height of interpapillary epithelium } \\
(\mu \mathrm{m})\end{array}$} & 1096.9 & 1067.1 & 1221.5 \\
\hline & & $\begin{array}{l}(519.2- \\
1374.2)\end{array}$ & $\begin{array}{l}(519.2- \\
1372.2)\end{array}$ & $\begin{array}{l}(1154.8- \\
1296.8)\end{array}$ \\
\hline \multirow{3}{*}{$\begin{array}{l}\text { Dorsal surface } \\
\text { of medial part } \\
\text { of torus }\end{array}$} & \multirow{2}{*}{$\begin{array}{l}\text { Height of stratified squamous } \\
\text { epithelium }(\mu \mathrm{m})\end{array}$} & 143.2 & 150.6 & 121.9 \\
\hline & & $\begin{array}{l}(21.9- \\
302.2)\end{array}$ & $\begin{array}{l}(64.5- \\
265.2)\end{array}$ & $(31.9-259.9)$ \\
\hline & \multirow{2}{*}{$\begin{array}{l}\text { Height of keratinized layer of } \\
\text { epithelium }(\mu \mathrm{m})\end{array}$} & 29.2 & 37.1 & 35.8 \\
\hline$x$ & & $\begin{array}{l}(15.3- \\
83.6)\end{array}$ & $\begin{array}{l}(21.0- \\
65.8)\end{array}$ & $(12.9-98.1)$ \\
\hline
\end{tabular}




\begin{tabular}{|c|c|c|c|c|}
\hline & $\begin{array}{l}\text { Height of interpapillary epithelium } \\
(\mu \mathrm{m})\end{array}$ & $\begin{array}{l}1006.9 \\
(675.3- \\
1432.2)\end{array}$ & $\begin{array}{l}838.8 \\
(296.7- \\
1432.2)\end{array}$ & $\begin{array}{l}1897.8 \\
(1612.9- \\
2148.4)\end{array}$ \\
\hline $\begin{array}{l}\text { Dorsal surface } \\
\text { of posterior } \\
\text { part }\end{array}$ & $\begin{array}{l}\text { Height of stratified squamous } \\
\text { epithelium }(\mu \mathrm{m})\end{array}$ & $\begin{array}{l}112.9 \\
(47.4- \\
193.1)\end{array}$ & $\begin{array}{l}129.5 \\
(52.2- \\
259.9)\end{array}$ & $\begin{array}{l}113.3 \\
(31.2-211.2)\end{array}$ \\
\hline of torus & $\begin{array}{l}\text { Height of keratinized layer of } \\
\text { epithelium }(\mu \mathrm{m})\end{array}$ & $\begin{array}{l}17.2 \\
(6.7-39.2)\end{array}$ & $\begin{array}{l}19.2 \\
(9.8- \\
37.4)\end{array}$ & $\begin{array}{l}16.8 \\
(8.1-32.1)\end{array}$ \\
\hline (Min - Max) & $\begin{array}{l}\text { Height of interpapillary epithelium } \\
(\mu \mathrm{m})\end{array}$ & $\begin{array}{l}470.0 \\
(331.2- \\
640.5)\end{array}$ & $\begin{array}{l}680.7 \\
(397.4- \\
948.7)\end{array}$ & $\begin{array}{l}944.4 \\
(616.9- \\
1206.3)\end{array}$ \\
\hline $\begin{array}{l}\text { Lateral } \\
\text { surfaces } \\
\text { of torus }\end{array}$ & $\begin{array}{l}\text { Height of stratified squamous } \\
\text { epithelium }(\mu \mathrm{m})\end{array}$ & $\begin{array}{l}147.1 \\
(56.8- \\
361.9)\end{array}$ & $\begin{array}{l}120.9 \\
(50.9- \\
236.9)\end{array}$ & $\begin{array}{l}121.2 \\
(34.3-216.9)\end{array}$ \\
\hline $\mathrm{X}$ & $\begin{array}{l}\text { Height of keratinized layer of } \\
\text { epithelium }(\mu \mathrm{m})\end{array}$ & $\begin{array}{l}31.5 \\
(14.8- \\
74.3)\end{array}$ & $\begin{array}{l}20.9 \\
(9.4- \\
68.1)\end{array}$ & $\begin{array}{l}17.7 \\
(5.8-41.9)\end{array}$ \\
\hline & $\begin{array}{l}\text { Height of interpapillary epithelium } \\
(\mu \mathrm{m})\end{array}$ & $\begin{array}{l}1205.3 \\
(864.5- \\
1577.9)\end{array}$ & $\begin{array}{l}1147.8 \\
(864.5- \\
1423.0)\end{array}$ & $\begin{array}{l}1408.9 \\
(1181.8- \\
1535.5)\end{array}$ \\
\hline
\end{tabular}

Table 5. The diameter of taste buds in cattle, European bison, and Bison bonasus hybrid 


\begin{tabular}{|c|c|c|c|}
\hline & Cattle & European bison & Bison bonasus hybrid \\
\hline Parts of tongue & $\begin{array}{l}\text { Diameter of taste buds } \\
(\mu \mathrm{m}) \\
\mathbf{X} \\
(\text { Min - Max })\end{array}$ & $\begin{array}{l}\text { Diameter of taste buds } \\
(\mu \mathrm{m}) \\
\mathbf{X} \\
(\text { Min - Max })\end{array}$ & $\begin{array}{l}\text { Diameter of taste buds } \\
(\mu \mathrm{m}) \\
\mathbf{X} \\
(\text { Min - Max })\end{array}$ \\
\hline $\begin{array}{l}\text { Dorsal surface } \\
\text { of the apex }\end{array}$ & $\begin{array}{l}40.9 \\
(29.9-62.9)\end{array}$ & $\begin{array}{l}47.9 \\
(38.7-57.5)\end{array}$ & $\begin{array}{l}32.5 \\
(30.2-32.5)\end{array}$ \\
\hline $\begin{array}{l}\text { Ventral surface } \\
\text { of the apex }\end{array}$ & $\begin{array}{l}39.5 \\
(31.0-51.9)\end{array}$ & $\begin{array}{l}41.7 \\
(29.6-52.5)\end{array}$ & $\begin{array}{l}42.6 \\
(29.6-63.9)\end{array}$ \\
\hline $\begin{array}{l}\text { Dorsal surface } \\
\text { of the lingual } \\
\text { body }\end{array}$ & $\begin{array}{l}41.2 \\
(30.2-55.6)\end{array}$ & $\begin{array}{l}42.4 \\
(29.0-54.8)\end{array}$ & $\begin{array}{l}45.2 \\
(39.5-56.4)\end{array}$ \\
\hline $\begin{array}{l}\text { Dorsal surface } \\
\text { of medial part } \\
\text { of torus }\end{array}$ & $\begin{array}{l}41.1 \\
(37.1-45.7)\end{array}$ & $\begin{array}{l}45.1 \\
(30.6-58.0)\end{array}$ & $\begin{array}{l}42.2 \\
(25.9-56.5)\end{array}$ \\
\hline $\begin{array}{l}\text { Dorsal surface } \\
\text { of posterior part } \\
\text { of torus }\end{array}$ & $\begin{array}{l}40.6 \\
(30.1-49.4)\end{array}$ & $\begin{array}{l}42.9 \\
(29.9-56.0)\end{array}$ & $\begin{array}{l}36.5 \\
(25.8-60.1)\end{array}$ \\
\hline $\begin{array}{l}\text { Lateral surfaces } \\
\text { of torus }\end{array}$ & $\begin{array}{l}\mathbf{4 4 . 8} \\
(32.2-63.0)\end{array}$ & $\begin{array}{l}38.8 \\
(23.8-56.1)\end{array}$ & $\begin{array}{l}36.9 \\
(24.2-50.3)\end{array}$ \\
\hline
\end{tabular}

\section{Figures}


Cattle
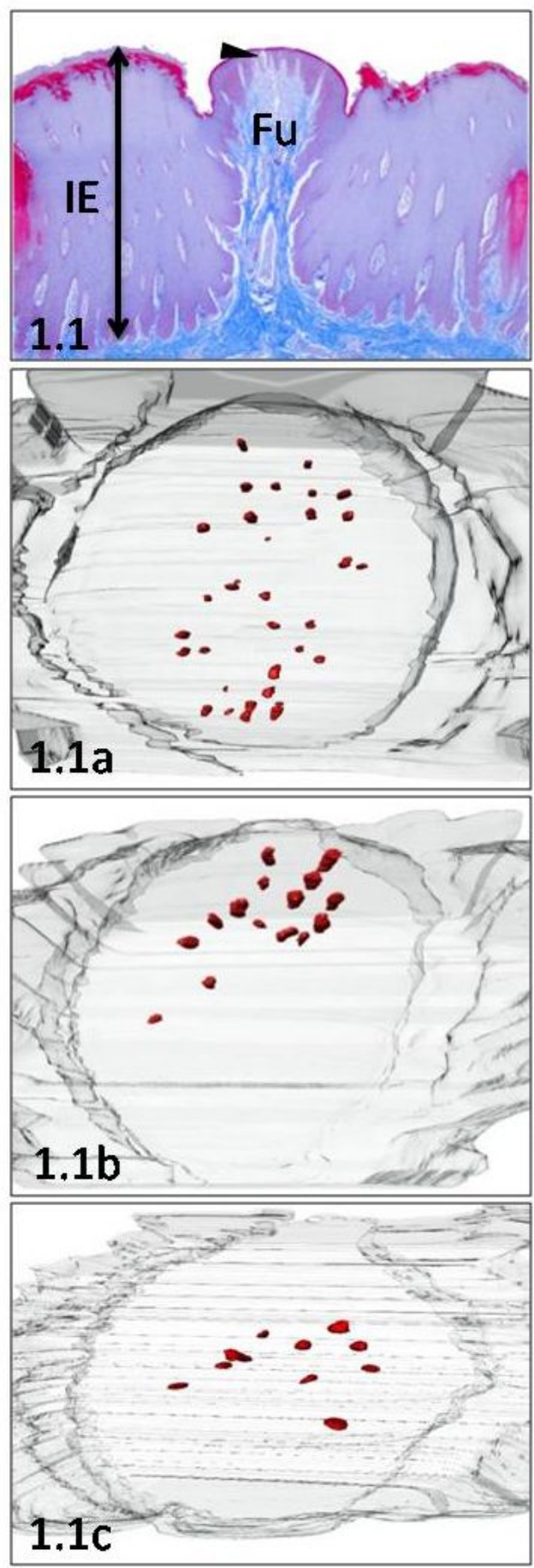

European bison
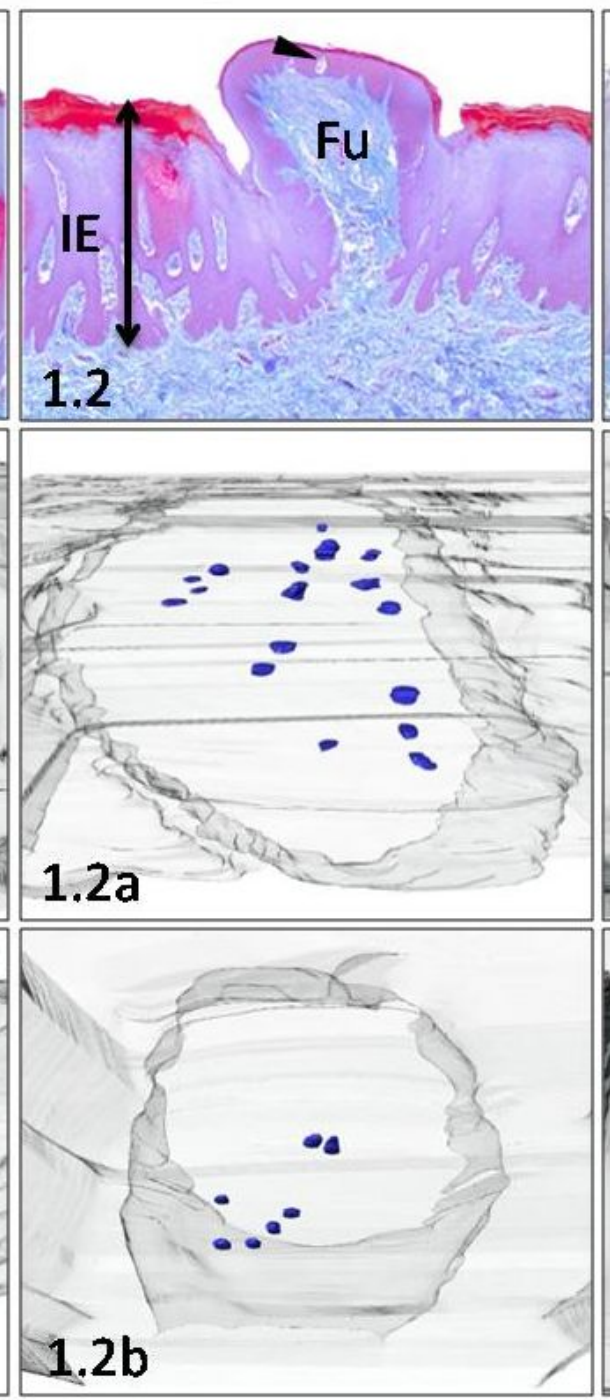

Bison bonasus hybrid
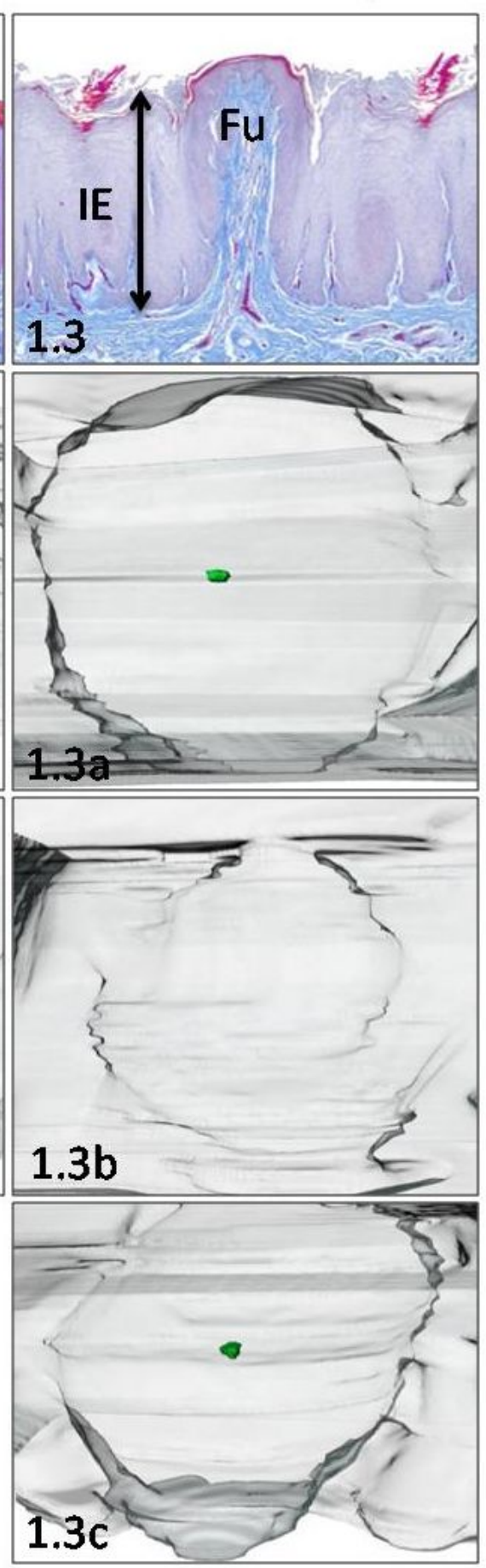

\section{Posterior direction}

\section{Figure 1}

Dorsal surface of the apex. The Fu papillae and its three-dimensional reconstructions on the dorsal surface of the apex in cattle (1.1), European bison (1.2), and Bison bonasus hybrid (1.3). Fu - fungiform papillae, IE - interpapillary epithelium, black arrowhead - taste buds. Taste buds on 3D models - red dots (cattle), blue dots (European bison), green dots (Bison bonasus hybrid 


\section{Cattle}
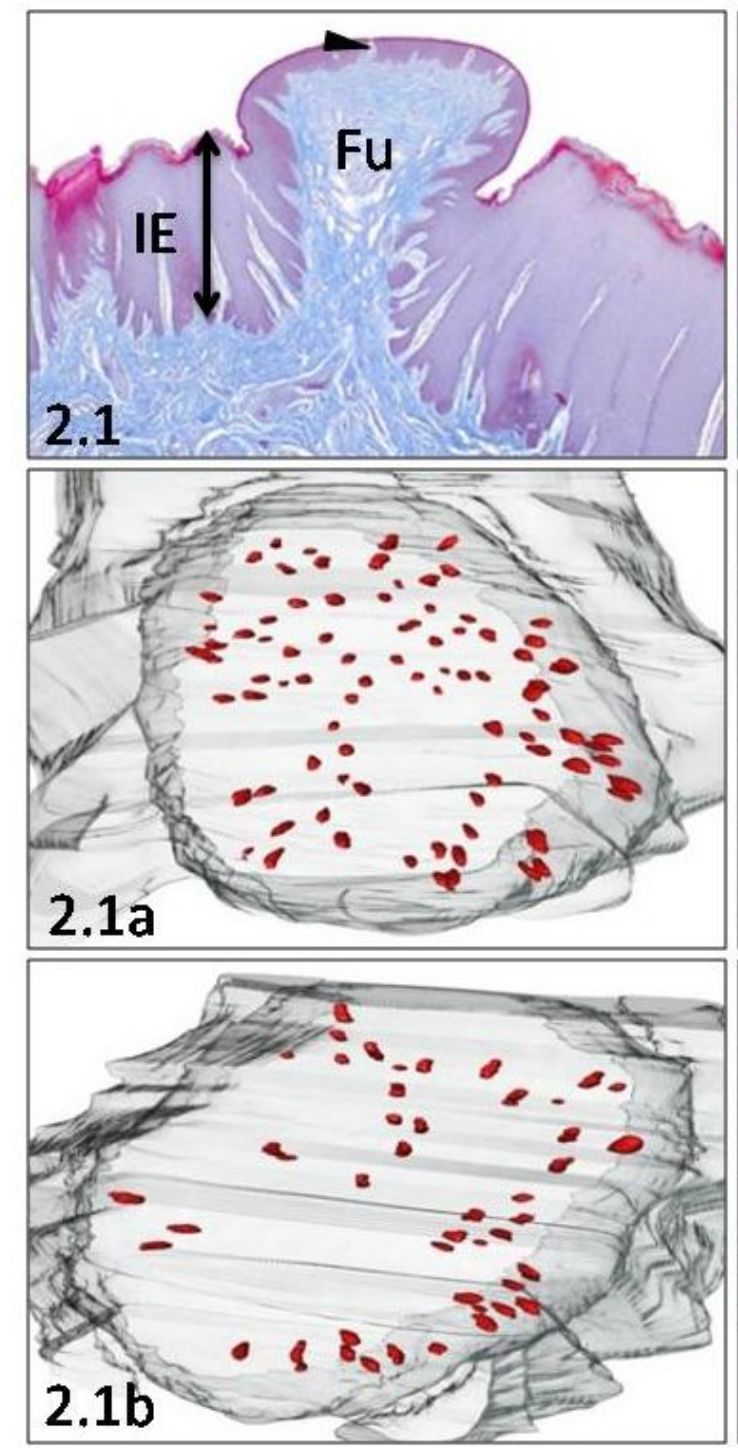

\section{European bison}
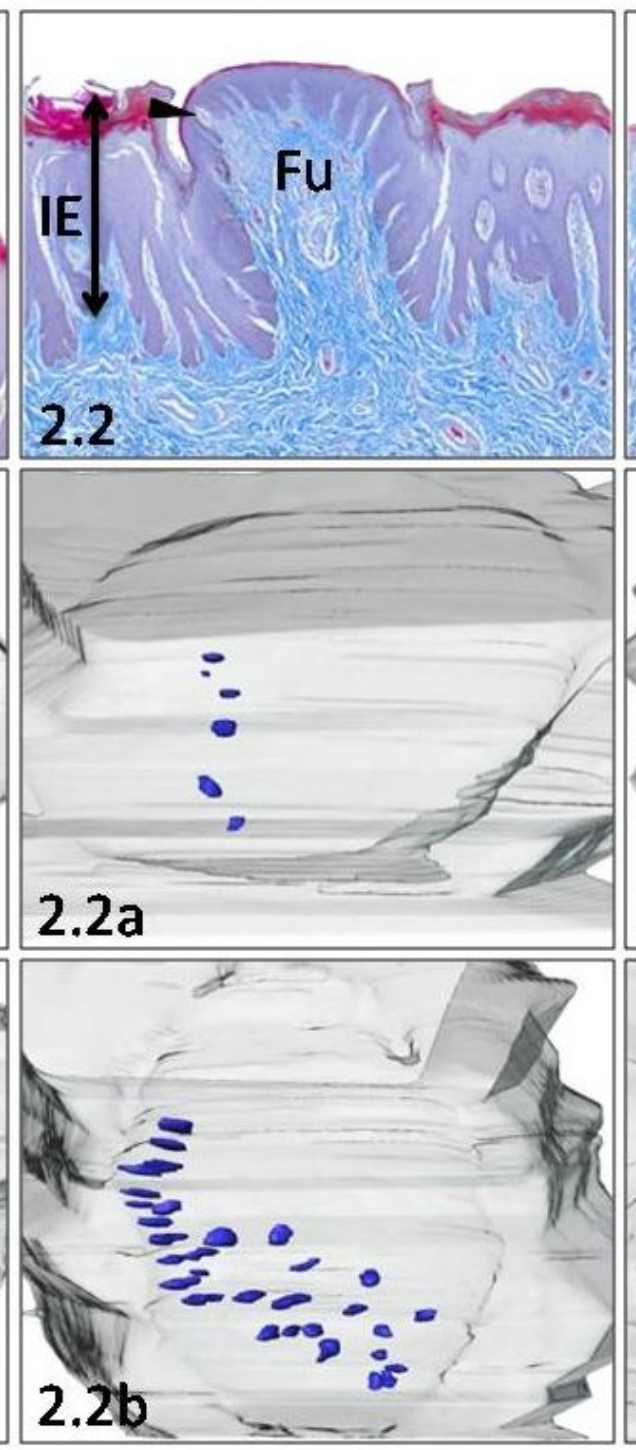
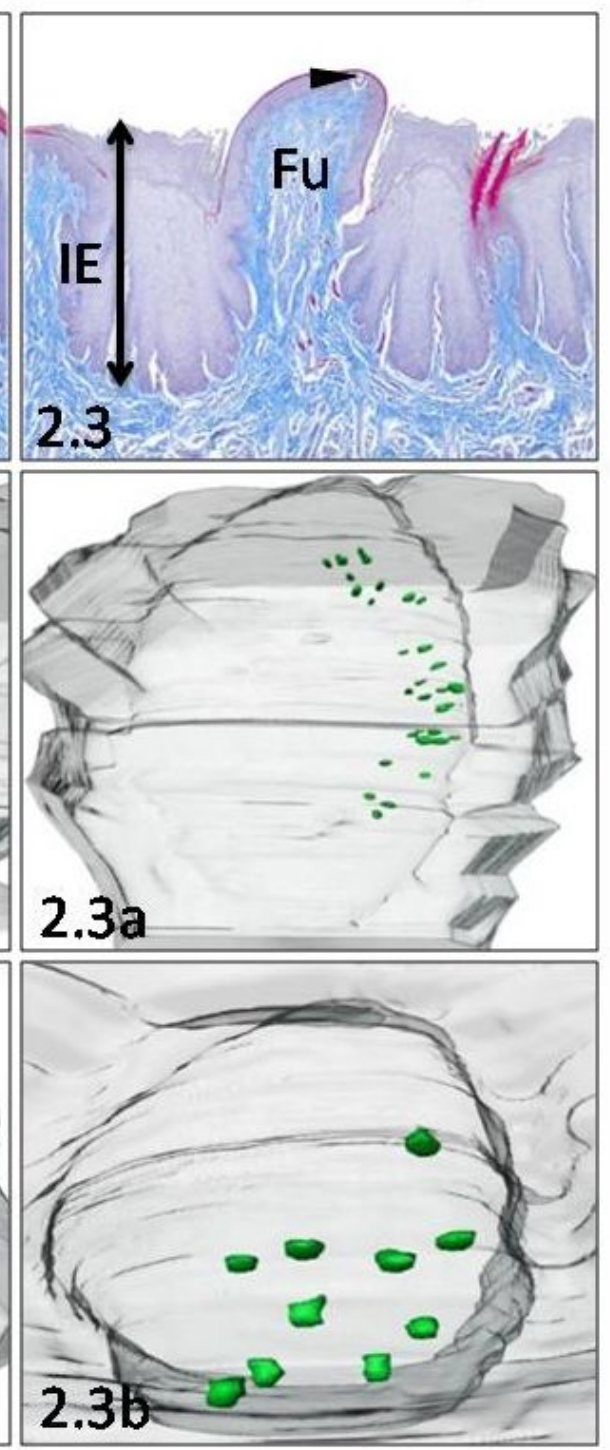

Lateral direction

Figure 2

Ventral surface of the apex. The Fu papillae and its three-dimensional reconstructions on the ventral surface of the apex in cattle (2.1), European bison (2.2), and Bison bonasus hybrid (2.3). Fu - fungiform papillae, IE - interpapillary epithelium, black arrowhead - taste buds. Taste buds on 3D models - red dots (cattle), blue dots (European bison), green dots (Bison bonasus hybrid) 


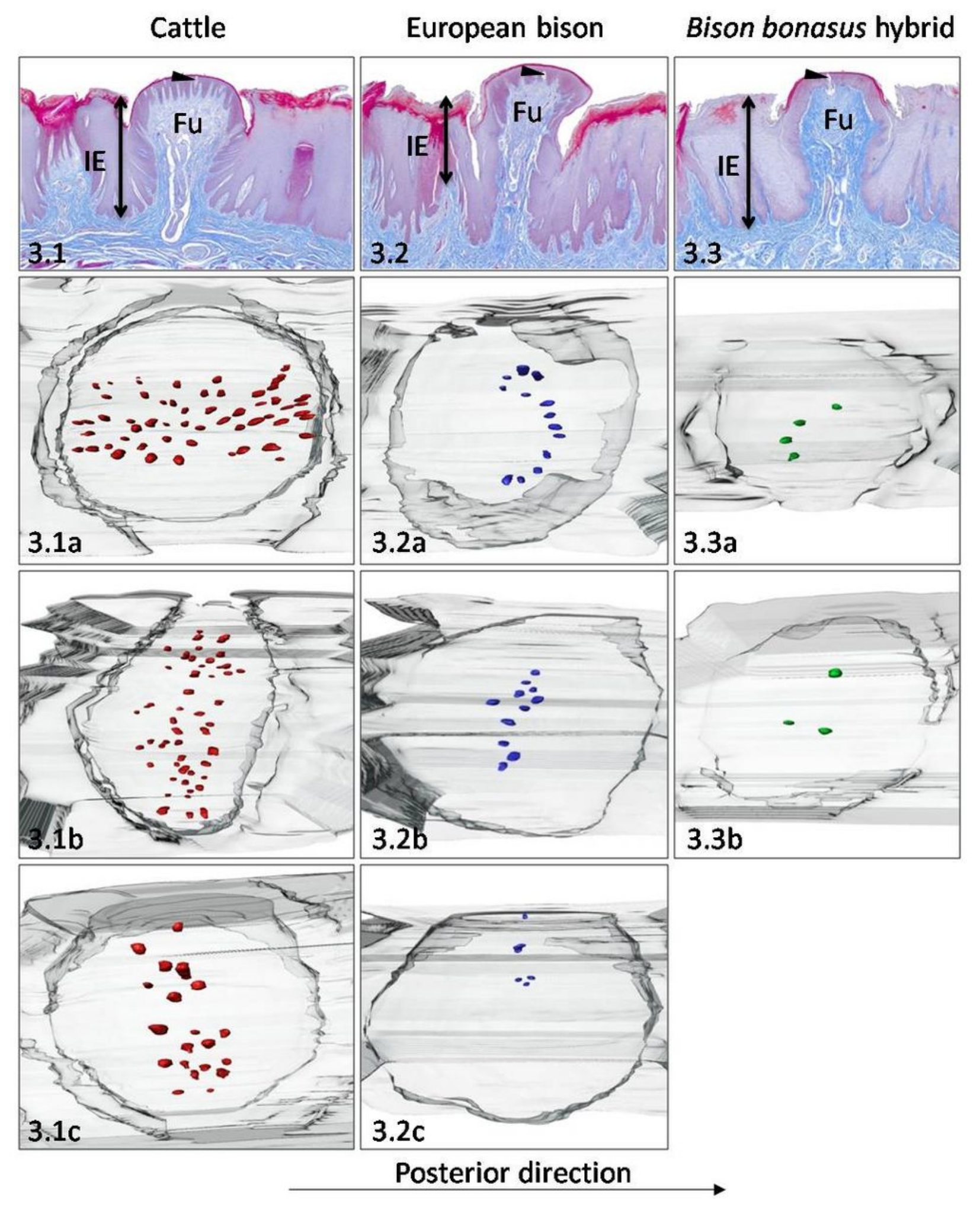

Figure 3

Dorsal surface of the lingual body. The Fu papillae and its three-dimensional reconstructions on the dorsal surface of the lingual body in cattle (3.1), European bison (3.2), and Bison bonasus hybrid (3.3). Fu - fungiform papillae, IE - interpapillary epithelium, black arrowhead - taste buds. Taste buds on 3D models - red dots (cattle), blue dots (European bison), green dots (Bison bonasus hybrid) 
Cattle
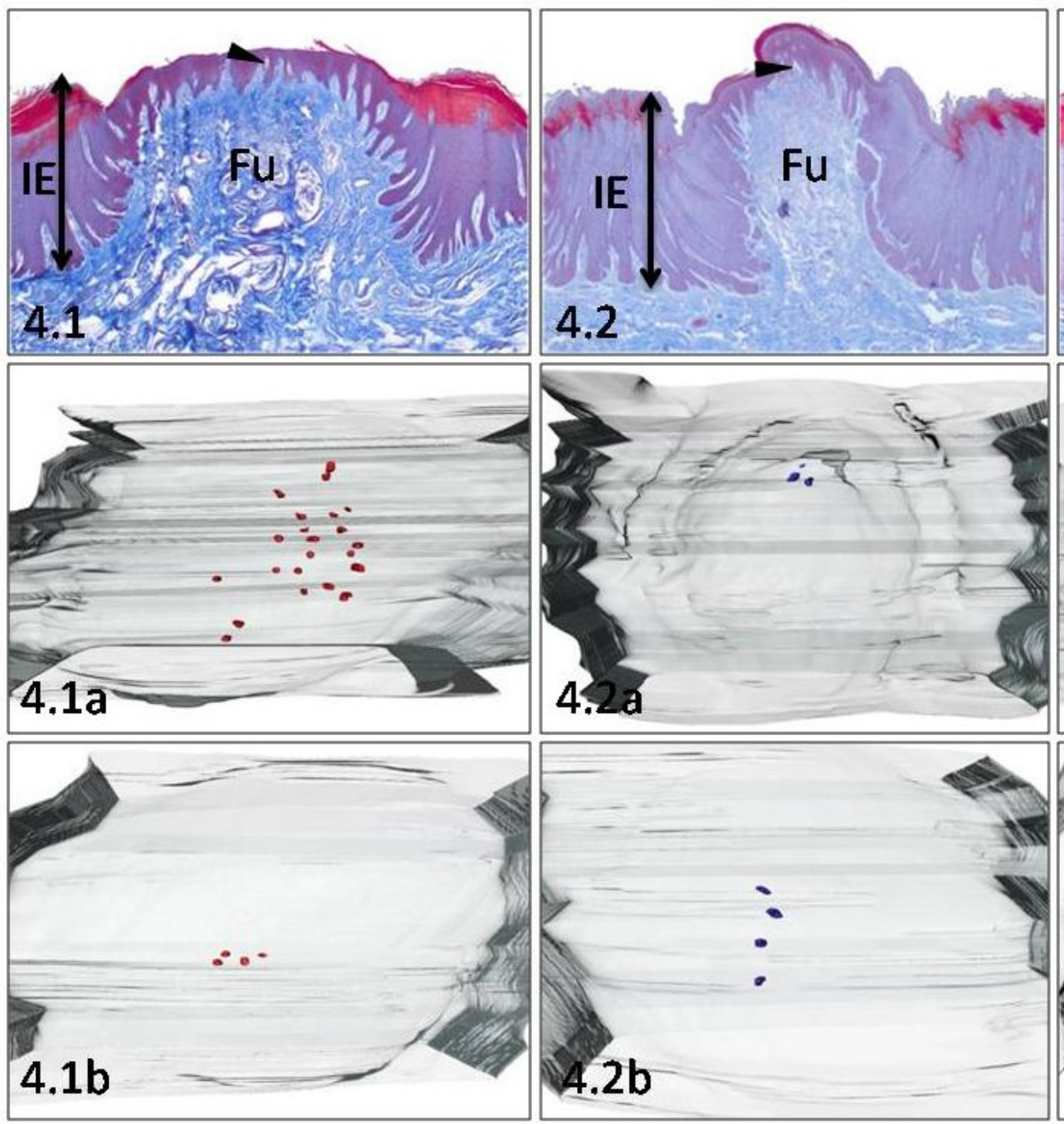

4

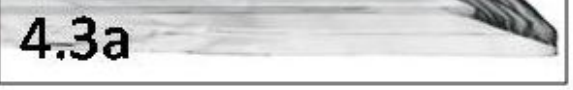

\section{Posterior direction}

\section{Figure 4}

Dorsal surface of the medial part of the torus. The Fu papillae and its three-dimensional reconstructions on the dorsal surface of the medial part of the torus in cattle (4.1), European bison (4.2), and Bison bonasus hybrid (4.3). Fu - fungiform papillae, IE - interpapillary epithelium, black arrowhead - taste buds. Taste buds on 3D models - red dots (cattle), blue dots (European bison), green dots (Bison bonasus hybrid) 


\section{Cattle}
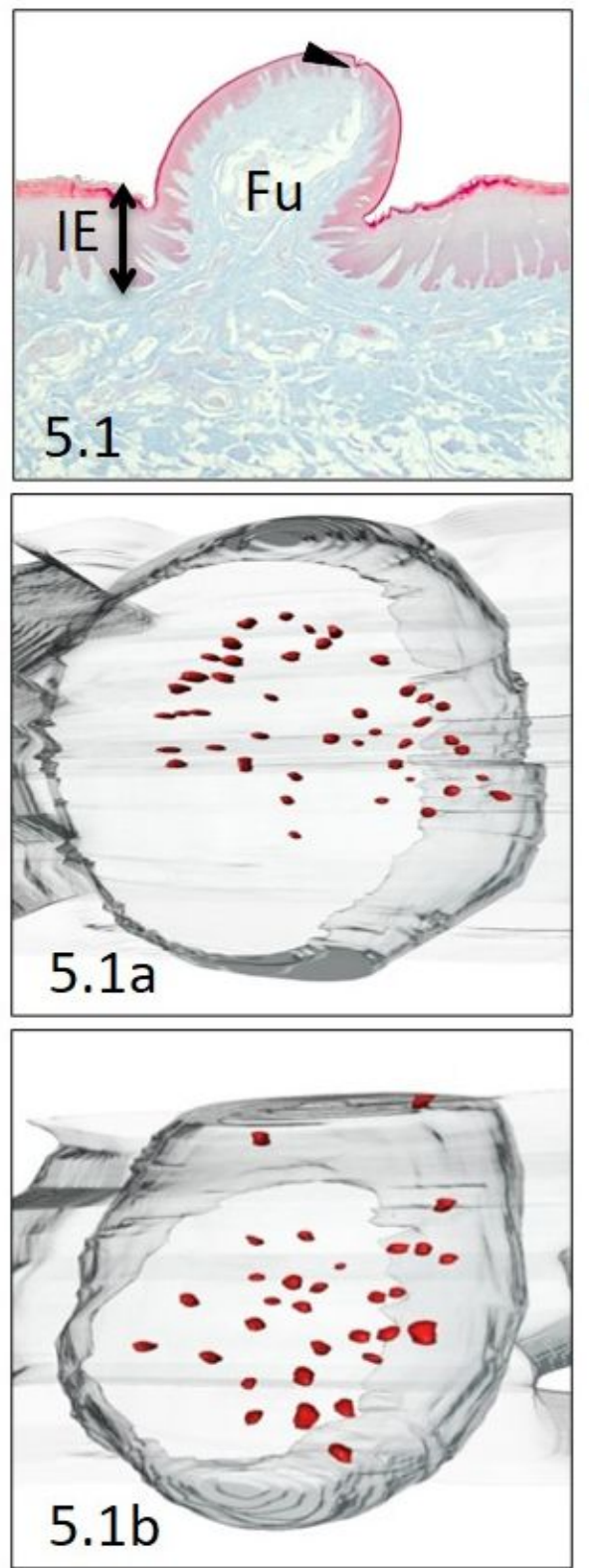

European bison
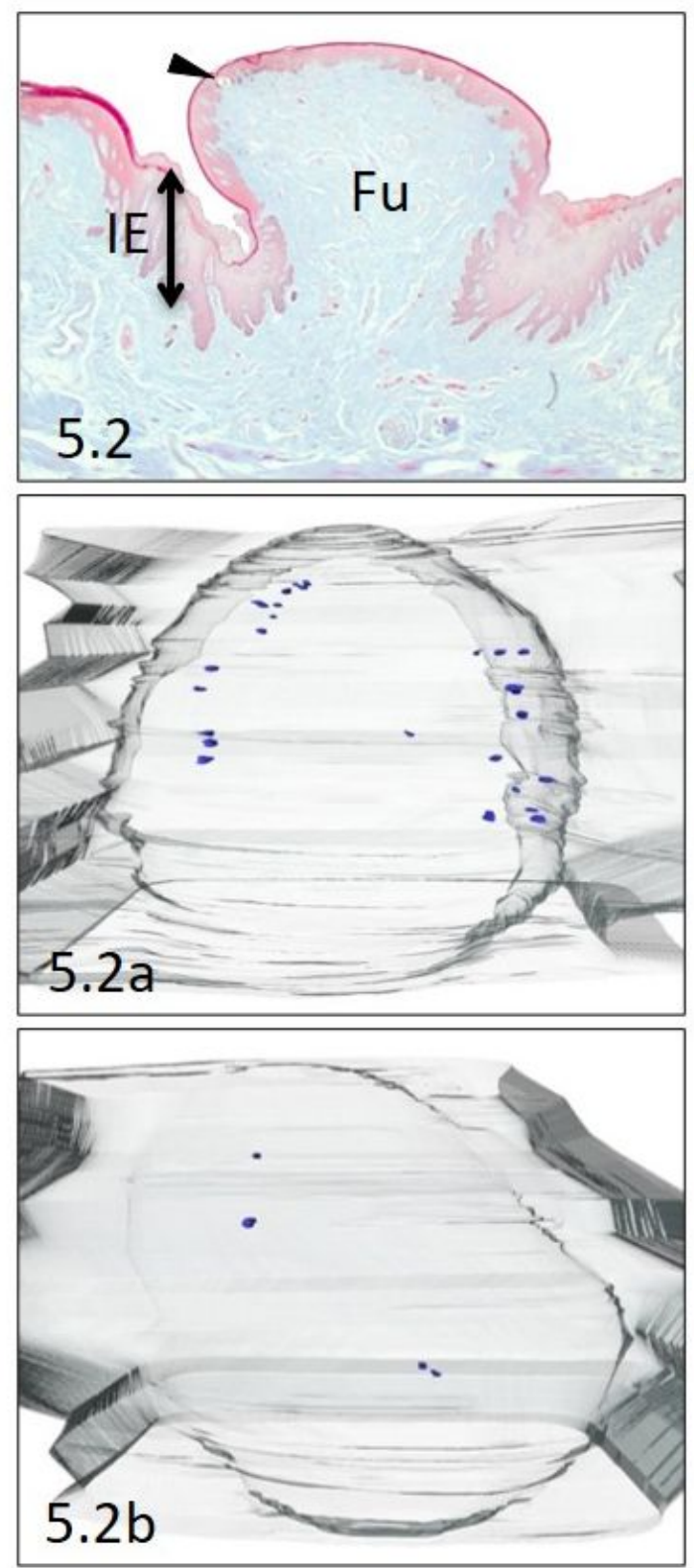

Bison bonasus hybrid
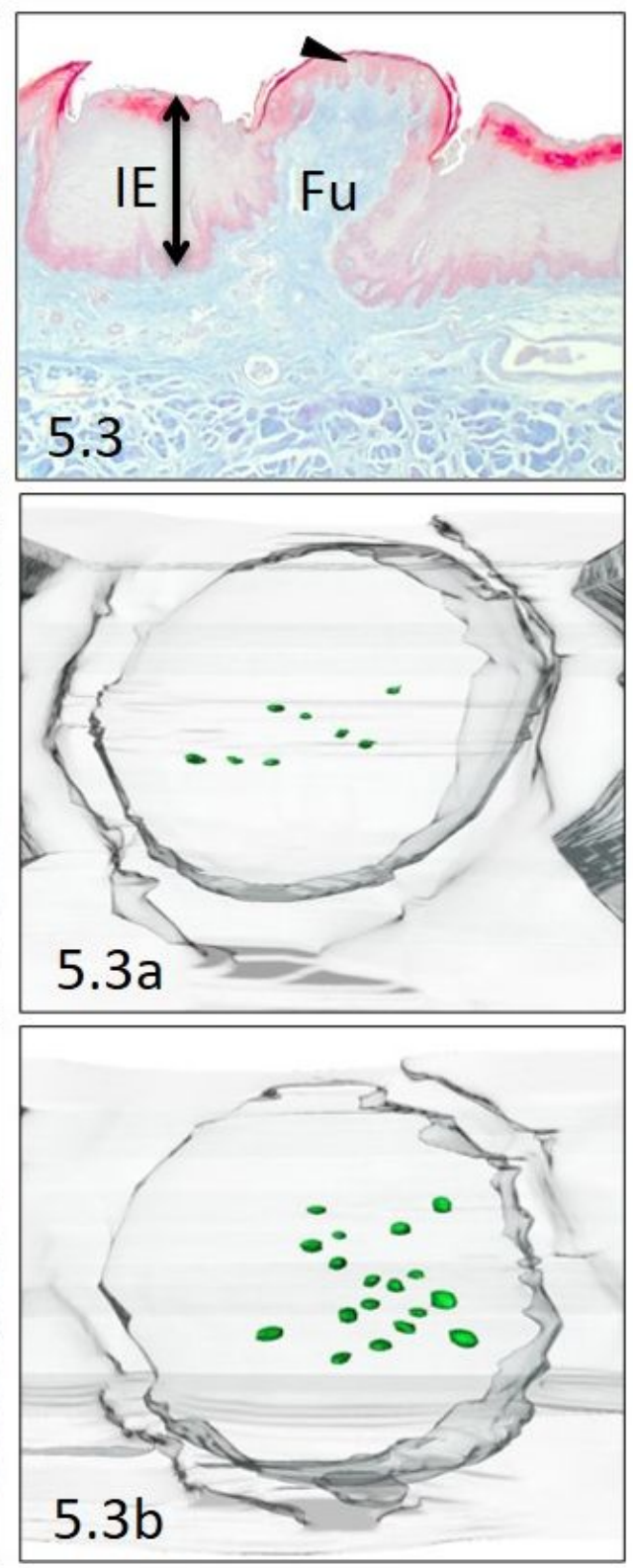

Posterior direction

\section{Figure 5}

Dorsal surface of the posterior part of the torus. The Fu papillae and its three-dimensional reconstructions on the dorsal surface of the posterior part of the torus in cattle (5.1), European bison (5.2), and Bison bonasus hybrid (5.3). Fu - fungiform papillae, IE - interpapillary epithelium, black arrowhead - taste buds. Taste buds on 3D models - red dots (cattle), blue dots (European bison), green dots (Bison bonasus hybrid) 


\section{Cattle}
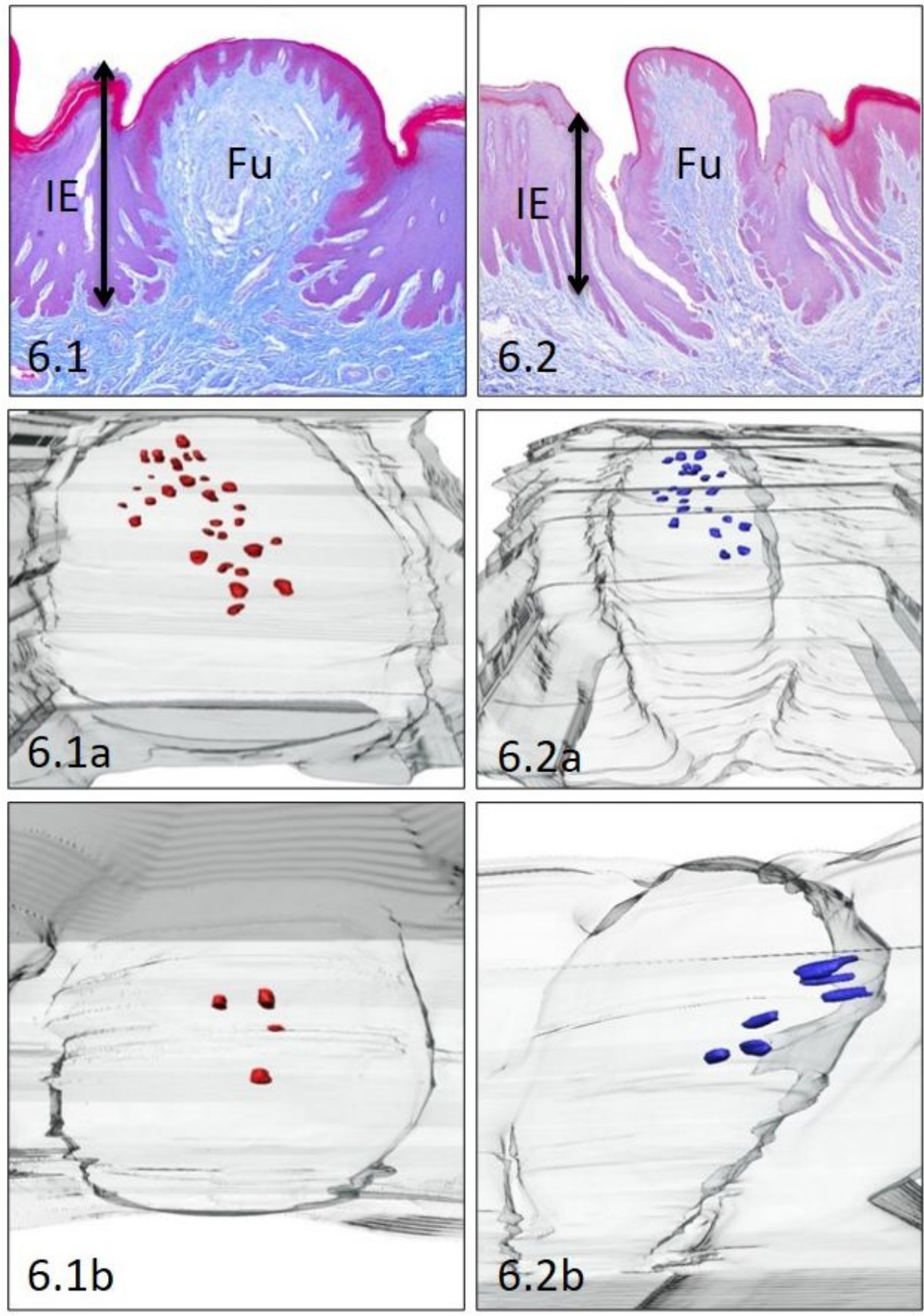

European bison
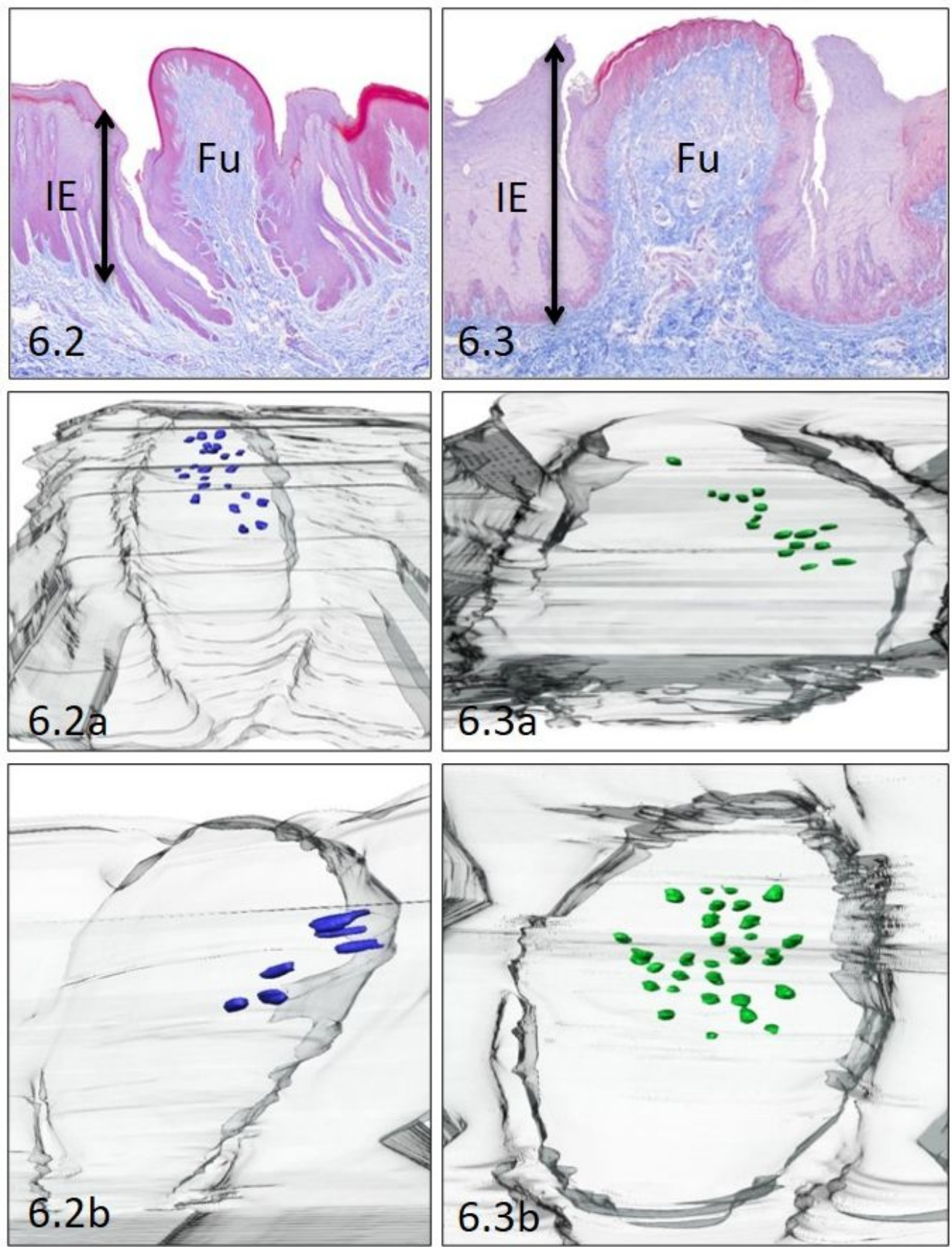

\section{Posterior direction}

\section{Figure 6}

Lateral surfaces of the torus. The Fu papillae and its three dimensional reconstructions on lateral surfaces of the torus in cattle (6.1), European bison (6.2) and Bison bonasus hybrid (6.3). Fu - fungiform papillae, IE - interpapillary epithelium, black arrowhead - taste buds. Taste buds on 3D models - red dots (cattle), blue dots (European bison), green dots (Bison bonasus hybrid) 

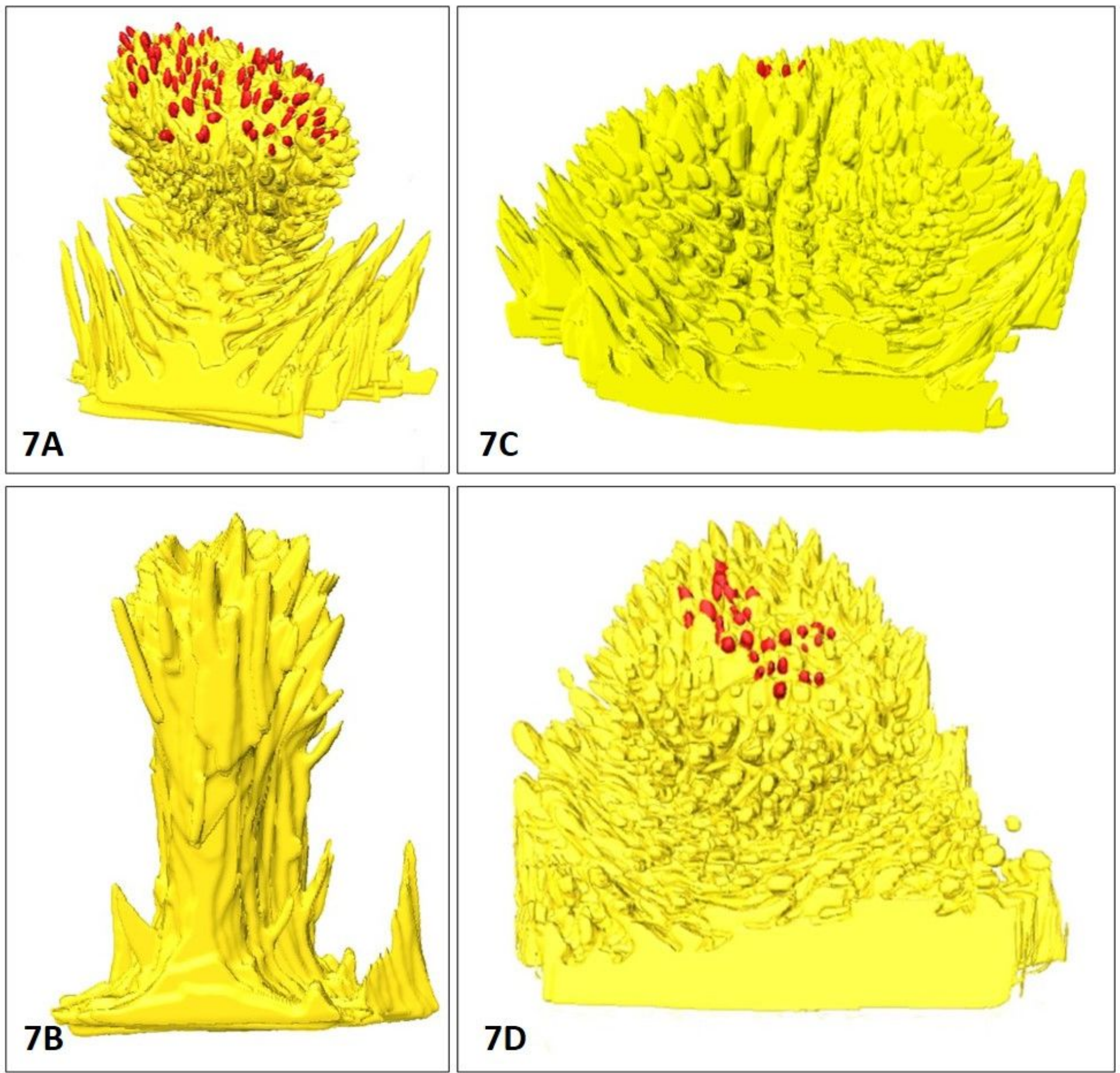

Figure 7

The types of connective tissue cores (CTC) of Fu papillae in cattle, European bison, and Bison bonasus hybrid. 7A - balloon-like CTC on the ventral surface of the apex in cattle, 7B - columnar-like CTC on the dorsal surface of the apex in Bison bonasus hybrid, $7 \mathrm{C}$ - cone-like CTC on the dorsal surface of the torus in cattle, 7D - cone-like CTC on lateral surfaces of the torus in cattle. Red dots - taste buds 


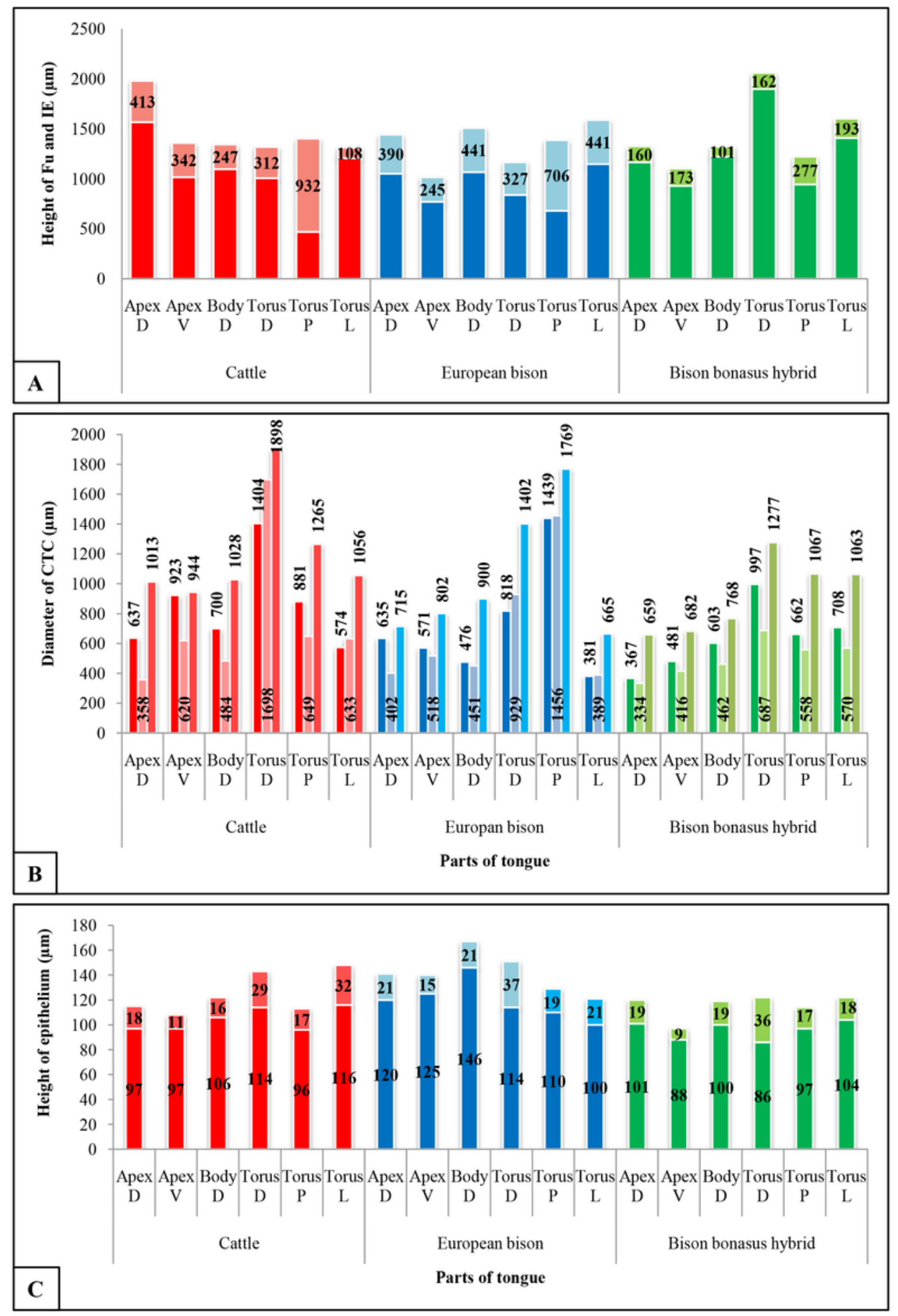

Figure 8

Graphical results of calculated data obtained during conducted studies in cattle, European bison, and Bison bonasus hybrid. A - the height of Fu papillae and interpapillary epithelium (IE) with the papillary protrusion (brighter colors) above the interpapillary epithelium (darker colors), B - the diameter of connective tissue cores (CTCs) on its dorsal (the darkest colors), medial (the brightest colors), and basal (intermediate colors) part in Fu papillae, $\mathrm{C}$ - the height of stratified squamous epithelium and its 
keratinized layer (brighter colors) on the apical surface of Fu papillae. Apex D - dorsal surface of the apex, Apex $V$ - ventral surface of the apex, Body $D$ - dorsal surface of the lingual body, Torus $D$ - dorsal surface of medial part of torus, Torus $P$ - dorsal surface of posterior part of torus, Torus $L$ - lateral surfaces of torus.

\section{Supplementary Files}

This is a list of supplementary files associated with this preprint. Click to download.

- Additionalfile1.mp4 